\title{
Potassium Isotope Compositions of Carbonaceous and Ordinary Chondrites: Implications on the Origin of Volatile Depletion in the Early Solar System
}

\author{
Hannah Bloom ${ }^{1}$, Katharina Lodders ${ }^{1}$, Heng Chen $^{1,2}$, Chen Zhao ${ }^{1,3}$, Zhen Tian ${ }^{1}$, Piers \\ Koefoed $^{1}$, Mária K. Petö ${ }^{4}$, Yun Jiang ${ }^{5,6}$, and Kun Wang (王昆) $)^{1^{*}}$
}

${ }^{1}$ Department of Earth and Planetary Sciences and McDonnell Center for the Space Sciences, Washington University in St. Louis, One Brookings Drive, St. Louis, MO 63130, USA

${ }^{2}$ Lamont-Doherty Earth Observatory, Columbia University, Palisades, NY 10964, USA

${ }^{3}$ Faculty of Earth Sciences, China University of Geosciences, Wuhan, Hubei 430074, China

${ }^{4}$ Konkoly Observatory, Research Center for Astronomy and Earth Sciences, H-1121 Budapest, Hungary

${ }^{5}$ CAS Key Laboratory of Planetary Sciences, Purple Mountain Observatory, Chinese Academy of Sciences, Nanjing 210008, China

${ }^{6} \mathrm{CAS}$ Center for Excellence in Comparative Planetology, China

*Corresponding author email: wangkun@,wustl.edu

Accepted version

\section{Geochimica et Cosmochimica Acta}

\section{How to cite:}

Bloom, H., Lodders, K., Chen, H., Zhao, C., Tian, Z., Koefoed, P., Pető, M. K., Jiang, Y., and Wang, K. (2020) Potassium isotope compositions of carbonaceous and ordinary chondrites: Implications on the origin of volatile depletion in the early solar system. Geochimica et Cosmochimica Acta, in press. 


\begin{abstract}
Among solar system materials there are variable degrees of depletion in moderately volatile elements (MVEs, such as $\mathrm{Na}, \mathrm{K}, \mathrm{Rb}, \mathrm{Cu}$, and $\mathrm{Zn}$ ) relative to the proto-solar composition. Whether these depletions are due to nebular and/or parent-body (asteroidal or planetary) processes is still under debate. In order to help decipher the MVE abundances in early solar system materials, we conducted a systematic study of highprecision $\mathrm{K}$ stable isotopic compositions of a suite of whole-rock samples of wellcharacterized carbonaceous and ordinary chondrites. We analyzed 16 carbonaceous chondrites (CM1-2, CO3, CV3, CR2, CK4-5 and $\mathrm{CH} 3)$ and 28 ordinary chondrites covering petrological types 3 to 6 and chemical groups H, L, and LL. We observed significant $\mathrm{K}$ isotope $\left(\delta^{41} \mathrm{~K}\right)$ variations $(-1.54$ to $0.70 \%$ ) among the carbonaceous and ordinary chondrites. In general, the two major chondrite groups are distinct: The K isotope compositions of carbonaceous chondrites are largely higher than the Bulk Silicate Earth (BSE) value, whereas ordinary chondrites show $\mathrm{K}$ isotope compositions that are typically lower than the BSE value. Neither carbonaceous nor ordinary chondrites show clear/resolvable correlations between $\mathrm{K}$ isotopes and chemical groups, petrological types, shock levels, cosmic-ray exposure ages, fall/find occurrence, or terrestrial weathering. Importantly, the lack of a clear trend between $\mathrm{K}$ isotopes and $\mathrm{K}$ content among chondrites indicates that the $\mathrm{K}$ isotope fractionations were decoupled from the relative elemental $\mathrm{K}$ depletions, which is inconsistent with a single-stage partial vaporization or condensation process to account for these MVE depletion patterns among chondrites. The range of K isotope variations in the carbonaceous chondrites in this study is consistent with a fourcomponent (chondrule, refractory inclusion, matrix and water) mixing model that is able
\end{abstract}


to explain the bulk elemental and isotopic compositions of the main carbonaceous chondrite groups, but requires a fractionation in $\mathrm{K}$ isotopic compositions in chondrules. We propose that the major control of the isotopic compositions of group averages is condensation and/or vaporization in pre-accretional (nebular) environments that is preserved in the compositional variation of chondrules. Parent-body processes, such as aqueous alteration, thermal metamorphism, and metasomatism, can mobilize $\mathrm{K}$ and affect the $\mathrm{K}$ isotopes in individual samples. In the case of the ordinary chondrites, the full range of $\mathrm{K}$ isotopic variations can only be explained by the combined effects of the size and relative abundances of chondrules, parent-body aqueous and thermal alteration, and possible sampling bias. 


\section{INTRODUCTION}

Compared to the bulk composition of our solar system, represented by the solar photosphere and CI chondrites (Palme et al., 2014), other chondritic meteorites and in particular differentiated planetary bodies of the inner solar system such as the Earth, Moon, Mars, and asteroid 4 Vesta are depleted in moderately volatile elements (e.g., Davis 2006; Palme et al. 1988) (see Figure 1). Conventionally, the volatility of an element is defined by its $50 \%$ nebular condensation temperature $(T c)$ calculated with the initial solar nebula composition at $10^{-4}$ bars (e.g., Grossman and Larimer 1974; Lodders 2003). The "moderately volatile elements" (MVEs) are elements with $50 \% T c$ between $650 \mathrm{~K}$ and $1250 \mathrm{~K}$, such as $\mathrm{Na}, \mathrm{K}, \mathrm{Rb}, \mathrm{Cu}$, and $\mathrm{Zn}$. The MVEs of undifferentiated bodies (i.e., chondrites) are generally depleted within one order of magnitude compared to the CI chondrites, while those of differentiated planetary bodies such as the Moon and Vesta can be depleted by as much as two orders of magnitude (see Figure 1). These MVE depletions across the solar system are an intrinsic property of the overall solar system chemical structure.

Two scenarios have been suggested to explain these observations: One ascribing the fractionations to processes occurring in the solar nebula environment and the other to planetesimal/planet formation. Nebular MVE depletion mechanisms include:

1) initial incomplete condensation from the solar nebula (Wasson and Chou, 1974; Wai and Wasson, 1977; Humayun and Clayton, 1995; Cassen, 1996; Ciesla, 2008),

2) partial evaporation of interstellar dusts prior to incorporation into the solar nebula (Yin, 2005) or in the solar nebula (Huss et al., 2003; Huss, 2004);

3) mixing of chondrite components formed in distinct volatile-rich and volatile- 
poor reservoirs of the early Solar System (e.g., Alexander et al. 2001; Anders 1964; Shu et al. 1997);

Processes depleting MVEs during planetesimal/planet formation include:

4) accretional volatile loss (Ringwood, 1966; Albarède, 2009; Hin et al., 2017);

5) giant impacts (Paniello et al., 2012; Wang and Jacobsen, 2016b);

6) magma ocean degassing (Day and Moynier, 2014; Kato et al., 2015);

7) extraction into steam atmospheres and atmospheric loss (Fegley et al., 2016; Young et al., 2019).

If the volatile depletions occurred mainly in nebular environments, and planetary bodies simply inherited these depletions from their building-blocks (possibly some material akin to chondrites and their components), we should expect to observe at least some trends of volatile element depletions among undifferentiated, primitive meteorites. Indeed, such trends are seen for the different types of carbonaceous chondrites (CCs). However, the degree of depletion among primitive meteorites are much less than those observed in differentiated planetary materials. Compared to other chondrites, CI chondrites are not volatile-depleted, and their compositions are similar to that of the Sun (except for the highly volatile elements $\mathrm{H}, \mathrm{C}, \mathrm{N}, \mathrm{O}$, and noble gases). The abundances of volatile elements in other $\mathrm{CCs}$ decrease in the sequence of $\mathrm{CI}>\mathrm{CM}>\mathrm{CO}=\mathrm{CV}>\mathrm{CR}>\mathrm{CK}$ (Lodders and Fegley, 1998; Lodders, 2003) (see MVEs in Figure 1). Unlike the patterns of volatile depletions among differentiated planetary materials, the volatile depletions in the CCs are plausibly explained by fractional condensation (or evaporation) in the nebular environment. Among the ordinary chondrites (OCs) the relative MVE abundances are quite similar but clearly different from the trends in the $\mathrm{CC}$ groups 
(see Figure 1). Ordinary chondrites were subjected to various degrees of thermal alteration in their parent bodies, which caused larger heterogeneities in the meteorite samples for highly volatile elements $(50 \% T c<650 \mathrm{~K}$; e.g., $\mathrm{Cd}$, In, $\mathrm{Bi}$ and $\mathrm{Tl})$, while the abundances of the MVEs (except for siderophile MVEs) do not vary dramatically among the groups and petrological types of the OCs (Wasson and Chou, 1974).

The isotopic compositions of the MVEs are promising tools for determining and distinguishing between the various processes proposed for producing the MVE fractionations (e.g., Humayun and Clayton 1995). Incomplete condensation or partial evaporation under different P-T conditions would generate different magnitudes of either equilibrium or kinetic isotopic fractionations (e.g., Richter et al. 2009). For example, upon heating dust at low ambient vapor pressures $\mathrm{P}_{\text {vap }}\left(<<\mathrm{P}_{\text {sat }}\right.$; saturation vapor pressure $)$, net evaporation and kinetic isotope fractionation become dominant. In contrast, when $\mathrm{P}_{\mathrm{vap}}$ $=\mathrm{P}_{\text {sat }}$, the system reaches equilibrium and only (small) equilibrium isotopic fractionation occurs. Thus, studying the isotopic compositions of the MVEs in CCs and OCs could constrain the conditions (e.g., ambient vapor pressure) where the MVEs were depleted.

Potassium is a moderately volatile element with a $50 \% T c$ of $\sim 1006 \mathrm{~K}$ (Lodders, 2003). The isotopes of $\mathrm{K}$ have been studied as a potential tracer of volatile depletion as early as 1995 (Humayun and Clayton, 1995). At that time, no variations between differentiated and undifferentiated meteorites were observed due to the relatively large analytical uncertainties using Secondary Ion Mass Spectrometry (SIMS). Since 2016, high-precision $\mathrm{K}$ isotope analytical methods using Multi-Collector Inductively-CoupledPlasma Mass-Spectrometry (MC-ICP-MS) (Wang and Jacobsen, 2016a; Li et al., 2016; Morgan et al., 2018; Hu et al., 2018) revealed resolvable variations in $\mathrm{K}$ isotopic 
compositions between different planetary materials (e.g., Earth and Moon) that were subsequently used to better understand the accretion mechanism of different planetary bodies.

Only a few high-precision $\mathrm{K}$ isotope data have been reported for chondrites since 2016: data are available for one CC (Orgueil, CI1) and three equilibrated OCs (Guareña, H6; Bruderheim and Peace River, L6) (Wang and Jacobsen, 2016b). Previous isotope studies of other moderately volatile elements such as $\mathrm{Zn}$ and $\mathrm{Rb}$ (Pringle et al., 2017; Pringle and Moynier, 2017) report relatively large isotopic fractionations among different $\mathrm{CC}$ and $\mathrm{OC}$ groups.

Here we present the first comprehensive dataset for high precision $\mathrm{K}$ isotopes for $16 \mathrm{CCs}$ and $28 \mathrm{OCs}$, which include most chemical and petrologic types of chondrites. This study will help compare chondritic materials to differentiated planetary materials, such as Earth, Moon, Mars and Vesta, by exploring and comparing the ranges of $\mathrm{K}$ isotopic fractionations. 


\section{SAMPLES and METHOD}

The sample names, chemical groups, petrological types, shock levels, and weathering grades of all the chondrites studied here are listed in Table $\mathbf{1}$ and $\mathbf{2}$. The acronyms in meteorites' names represent the places where they were found (e.g., ALH, EET, GRA, GRO, LAP, LAR, LON, MAC, MET, MIL, PCA, PRA, PRE, QUE, RBT, and RKP represent Allan Hills, Elephant Moraine, Graves Nunataks, Grosvenor Mountains, LaPaz Icefield, Larkman Nunatak, Lonewolf Nunatak, MacAlpine Hills, Meteorite Hills, Miller Range, Pecora Escarpment, Mount Pratt, Mount Prestrud, Queen Alexandra, Roberts Massif, and Reckling Peak, respectively). Our sample set covers all major chemical and petrological types of CC and OC. Eight of our samples are falls and 36 samples are finds from Antarctica. To minimize the potential effects from terrestrial weathering, we include only Antarctic finds that had been exposed to little or no weathering (classified as weathering grade " $\mathrm{A}$ " seen in Table 1 and 2). Previous studies have shown that the Antarctic meteorites are well preserved and have little terrestrial contamination (e.g., Crozaz and Wadhwa 2001). Tian et al. (2019) demonstrated that the $\mathrm{K}$ isotopes of Antarctic meteorites are indistinguishable from those of meteorite falls of the same type, in contrast to hot desert (e.g., NWA Northwest Africa) meteorites, which are significantly contaminated by terrestrial $\mathrm{K}$ or/and altered due to terrestrial weathering.

Details of our analytical method can be found in Chen et al. (2019). For all samples, chips (free of fusion crust) were selected and finely ground using an agate pestle and mortar. About 100-200 mg of the well-mixed powders were dissolved for $\mathrm{K}$ isotope analysis (see Table 1 and 2 for the mass dissolved for each sample). All samples were digested using Parr high-pressure digestion vessels at $150{ }^{\circ} \mathrm{C}$ in a Quincy Lab Model 10 
lab oven for two days through a two-step protocol (first in concentrated $\mathrm{HF} / \mathrm{HNO}_{3}$ mixture and then in aqua regia). Fully digested samples were dried down and refluxed with $0.7 \mathrm{~N} \mathrm{HNO}_{3}$. Then samples were loaded into chromatography columns (ID $=1.5 \mathrm{~cm}$; filled with 17 mL Bio-Rad AG50W-X8 100-200 mesh cation exchange resin). Potassium was eluted and collected with $0.7 \mathrm{~N} \mathrm{HNO}_{3}$. To further purify $\mathrm{K}$ from matrix elements, we repeated the same procedure a second time using a smaller column ( $\mathrm{ID}=0.5 \mathrm{~cm}$; filled with $2.4 \mathrm{~mL}$ resin). The yield of the procedure is $>99 \%$. The total-procedure blank is $0.26 \pm 0.15 \mu \mathrm{g}(2 \mathrm{SD} ; \mathrm{n}=7$; Chen et al. 2019) and is negligible $(<1 \%)$ compared to the amount of $\mathrm{K}$ in the samples.

The concentrations of $\mathrm{K}$ and matrix elements after columns were measured with a Thermo Scientific iCapQ quadrupole ICP-MS. The $\mathrm{K}$ isotopic compositions were measured with a Thermo Scientific Neptune Plus MC-ICP-MS using the sample-standard bracketing (SSB) method. All $\mathrm{K}$ isotopic data is expressed in the delta notation, where $\delta^{41} \mathrm{~K}=\left[\left({ }^{41} \mathrm{~K} /{ }^{39} \mathrm{~K}\right)_{\text {sample }} /\left({ }^{41} \mathrm{~K} /{ }^{39} \mathrm{~K}\right)_{\text {NIST SRM } 3141 \mathrm{a}}-1\right] \times 1000$. To monitor the data quality of each analytical session (24 hours), we measured a geostandard (BHVO-2) along with the chondrite samples. The typical within-session reproducibility is $\sim 0.05 \%$ ( $95 \%$ c.i.; confidence interval). The long-term ( $\sim 20$ months) reproducibility of this method has been evaluated as $0.11 \%$ (Chen et al. 2019), which is our most conservatively estimated analytical error. 


\section{RESULTS}

Results for the CCs are given in Table 1 and the OCs in Table 2, with data for the geostandard in each analytical campaign given in the respective tables. All individual sample errors are shown as $95 \%$ c.i. while all sample populations are shown as 2 standard deviation (2SD). Our determination of the $\mathrm{K}$ isotopic composition $\left(\delta^{41} \mathrm{~K}\right)$ of the basaltic geostandard BHVO-2 $(-0.47 \pm 0.03 \%$ and $-0.49 \pm 0.03 \%$; see Table 1 and 2$)$ agrees well with published data (ca. $-0.5 \pm 0.05 \%$; Hu et al. 2018; Li et al. 2016; Morgan et al. 2018; Wang and Jacobsen 2016b), which gives us confidence in the accuracy of our measurements.

\subsection{Potassium isotopic compositions of the carbonaceous chondrites}

Figure 2a illustrates the significant $\mathrm{K}$ isotopic fractionations in the different chemical groups of the CCs. The range of $\delta^{41} \mathrm{~K}$ for all $17 \mathrm{CCs}$ span from $-1.54 \pm 0.03 \%$ to $0.70 \pm 0.02 \%$. Excluding three extreme cases (MIL 11213 (CO3), LAR 12002 (CV3) and GRA 06100 (CR2)) the other $14 \mathrm{CCs}$ span a much more restricted range of $\delta^{41} \mathrm{~K}$ from $-0.64 \pm 0.03 \%$ to $-0.06 \pm 0.04 \%$, with an average (simple arithmetic mean) of $-0.29 \pm 0.34 \%$ (2SD).

The CI chondrite $\delta^{41} \mathrm{~K}$ value of $-0.53 \pm 0.11 \%$ from Wang and Jacobsen (2016a) is within the uncertainty of the Bulk Silicate Earth (BSE in Figure 2a). The four CM meteorites have a $\delta^{41} \mathrm{~K}$ range from $-0.39 \pm 0.03 \%$ to $-0.09 \pm 0.03 \%$, with a mean of $-0.25 \pm 0.26 \%$ (2SD). The range for the four $\mathrm{CO}$ meteorites is $-0.35 \pm 0.07 \% \leq \delta^{41} \mathrm{~K} \leq$ $0.36 \pm 0.05 \%$, averaging $-0.09 \pm 0.58 \%$ (2SD). One CV chondrite (LAR 12002) has the lowest $\delta^{41} \mathrm{~K}$ value of all samples analyzed in this study; the low value was confirmed 
with a second fragment from this meteorite $(-1.45 \pm 0.04 \%$ and $-1.54 \pm 0.03 \%$ ). The other two $\mathrm{CV}$ meteorites have a $\delta^{41} \mathrm{~K}$ range from $-0.53 \pm 0.03 \%$ o to $-0.30 \pm 0.02 \%$, averaging at $-0.39 \pm 0.25 \%$ (2SD). Only two fragments of a single CR meteorite (GRA $06100)$ were analyzed. Both fragments show high $\delta^{41} \mathrm{~K}$ values $(0.70 \pm 0.02 \%$ and $0.16 \pm$ $0.03 \%)$ with one of the two fragments showing the highest $\delta^{41} \mathrm{~K}$ value $(0.70 \pm 0.02 \%)$ of all the samples analyzed in this study. The four CK meteorites have a $\delta^{41} \mathrm{~K}$ range from $-0.36 \pm 0.03 \%$ to $-0.06 \pm 0.04 \%$, averaging at $-0.15 \pm 0.25 \%$ (2SD). The only $\mathrm{CH}$ meteorite in our study yields a $\delta^{41} \mathrm{~K}$ of $-0.64 \pm 0.03 \%$, slightly lighter than the BSE value. Of the $\mathrm{CC}$ samples analyzed here, the majority have heavier $\mathrm{K}$ isotopic compositions than that of the CI chondrites $(-0.53 \pm 0.11 \%$; Wang and Jacobsen 2016a) and the BSE (-0.48 $\pm 0.03 \%$; Wang and Jacobsen 2016b).

\subsection{Potassium isotopic compositions of the ordinary chondrites}

Figure $2 \mathbf{b}$ shows large variations in the $\mathrm{K}$ isotopic compositions $\left(\delta^{41} \mathrm{~K}\right.$ varying from $-1.47 \pm 0.06 \%$ to $0.07 \pm 0.03 \%$ ) of the OCs that were measured here. The ranges of $\delta^{41} \mathrm{~K}$ of the three OC groups (H, L, LL) overlap; however, on average the $\mathrm{H}$ group has slightly heavier compositions due to two $\mathrm{H}$ chondrites showing $\delta^{41} \mathrm{~K} \geq 0$ (RKPA 78004 and PRE 95400). The $\mathrm{H}$ group has a $\delta^{41} \mathrm{~K}$ range from $-1.28 \pm 0.05 \%$ to $0.07 \pm 0.03 \%$ o with an average $\delta^{41} \mathrm{~K}$ of $-0.70 \pm 0.81 \%$ (2SD). The $\mathrm{L}$ group range is $-1.14 \pm 0.03 \%$ s $\delta^{41} \mathrm{~K} \leq-0.54 \pm 0.10 \%$ with an average $\delta^{41} \mathrm{~K}$ of $-0.82 \pm 0.32 \%$ (2SD), and the LL group range is $-1.47 \pm 0.06 \%$ o $\leq \delta^{41} \mathrm{~K} \leq-0.44 \pm 0.05 \%$ with an average $\delta^{41} \mathrm{~K}$ of $-0.95 \pm 0.61$ \%o (2SD). Three OCs (one H6 and two L6) were analyzed previously (Wang and Jacobsen, 2016b) and they fall into the range of the OCs measured in this study. Our 
measurements show no systematic variations of $\mathrm{K}$ isotope compositions as a function of chemical group. The majority of the OC samples analyzed here have lighter $\mathrm{K}$ isotopic compositions than that of the CI chondrites $(-0.53 \pm 0.11 \%$; Wang and Jacobsen 2016a) and BSE $(-0.48 \pm 0.03 \%$; Wang and Jacobsen 2016b).

\subsection{Potassium isotopic heterogeneity in carbonaceous and ordinary chondrites}

\section{samples}

To examine the $\mathrm{K}$ isotopic heterogeneity within the same meteorite, for 16 different meteorites we conducted measurements two or three times on different fragments $(\sim 0.1 \mathrm{~g}$ each fragment; labeled as \#1, \#2,\#3 in Table 1 and 2$)$ of the same samples $(\sim 0.5-1 \mathrm{~g}$ each sample). Individual fragments were powdered, dissolved, purified and analyzed independently. Within our long-term reproducibility of $0.11 \%$ (Chen et al., 2019), different fragments of 9 out of 16 meteorites yield indistinguishable $\mathrm{K}$ isotope compositions. The different chips of the other 7 meteorites do not agree with each other within analytical uncertainty. The $\delta^{41} \mathrm{~K}$ differences between different fragments of these 7 samples vary by $0.14 \%$ (L3.6 GRO 06054), 0.18 \%о (LL5 RBT 04127), $0.19 \%$ \% (CV3 Allende), $0.27 \%$ (H4 Weston), $0.27 \%$ (L5 Homestead), $0.34 \%$ (CO3 MIL 11213), and $0.54 \%$ (CR2, GRA 06100). These compositional differences exceed analytical uncertainties and likely reflect the $\mathrm{K}$ isotope heterogeneity at the 0.1 -gram-scale within the samples. Note that the observed heterogeneity shows no relation to the sample type of $\mathrm{CC}$ and $\mathrm{OC}$ (e.g., $\mathrm{CV}, \mathrm{CO}, \mathrm{CR}, \mathrm{H}, \mathrm{L}$ and $\mathrm{LL})$. The causes of this $\mathrm{K}$ isotopic heterogeneity will be discussed in Section 4.2 and Section 4.3. 


\section{DISCUSSION}

\subsection{Effects of terrestrial weathering on potassium isotopes of chondrites.}

We chose to study both falls and finds to examine whether terrestrial weathering would affect the $\mathrm{K}$ isotope compositions of chondrites. Chondritic meteorites only contain 200-970 ppm K (Lodders and Fegley, 1998), which is significantly lower than the $\mathrm{K}$ abundance on the surface of the Earth (e.g., continental crust 23244 ppm; Rudnick and Gao 2014). Terrestrial weathering and contamination could potentially add terrestrial $\mathrm{K}$ to meteorite finds. "Hot desert" meteorite finds have been shown to have $\mathrm{K}$ addition compared to meteorite falls and Antarctic finds (Bischoff et al., 1998; Zipfel et al., 2000). In addition, K salts in chondrites (e.g., sylvite and halite; Rubin et al. 2002; Zolensky et al. 1999) are very soluble and could possibly be leached out during terrestrial weathering by rain or surface water. As a result, the $\mathrm{K}$ isotopic compositions of meteorite finds can be potentially altered.

Ideally, only samples recovered quickly from observed meteorite falls and wellcurated samples should be analyzed to circumvent potential terrestrial contamination and/or alteration. Nevertheless, Antarctic meteorites finds have generally been subjected to much less terrestrial weathering than "hot desert" meteorites (e.g., Crozaz and Wadhwa 2001). Furthermore, Tian et al. (2019) showed that the K isotopic compositions of eucrite meteorites from hot desert regions (e.g., NWA) have significantly higher K concentrations than eucrite falls and eucrite meteorites from Antarctica. The $\mathrm{K}$ isotopic compositions of NWA eucrite meteorites were also shown to be similar to those of terrestrial rocks and different from those of eucrite falls (Tian et al., 2019). In contrast, all eucrite meteorites from Antarctica have indistinguishable $\mathrm{K}$ isotopic compositions 
compared to eucrite falls. In general, eucrite meteorites contain a lower abundance of $\mathrm{K}$ (25 to 328 ppm; Lodders and Fegley 1998) when compared to chondritic meteorites (82 to $796 \mathrm{ppm}$; Table 1). Thus, chondritic meteorites from Antarctica are even less likely to be affected by terrestrial weathering when compared to eucrite meteorites from Antarctica. As such, we primarily studied Antarctic finds combined with available falls and completely avoided meteorites from "hot deserts".

As shown in Table 1 and Figure 3, there is no significant difference in the $\mathrm{K}$ isotope ranges between falls and Antarctic finds of the same chemical group. For example, the average $\delta^{41} \mathrm{~K}$ values for falls and Antarctic finds are $-0.92 \pm 0.50 \%$ (2SD) vs. $-0.49 \pm 0.86 \%$ (2SD) for the $H$ chemical group; $-0.78 \pm 0.44 \%$ (2SD) vs. $-0.84 \pm$ $0.19 \%$ (2SD) in the L chemical group; and $-0.94 \pm 0.64 \%$ (2SD) vs. $-1.04 \pm 0.08 \%$ (2SD) for LL chemical group respectively. For the CV group, the averages (excluding the outlier LAR 12002) are $-0.44 \pm 0.27 \%$ vs. $-0.30 \pm 0.02 \%$, respectively. All Antarctic meteorites have been assigned a letter to indicate their weathering grades. Letters A, B or $\mathrm{C}$ represents "minor", "moderate" or "severe" rustiness, respectively. An additional letter "e" denotes the presence of visible evaporite minerals. Figure 3 plots all the samples, K isotopic compositions vs. their weathering grades, and shows no correlation in any of the chemical groups. Therefore, we concluded that the majority of Antarctic meteorites (except the outlier LAR 12002) studied here were not measurably contaminated or altered by terrestrial weathering. Terrestrial weathering is a potential problem for acquiring the pristine $\mathrm{K}$ isotopic compositions of meteorite finds, however this is mostly restricted to meteorites from hot-desert regions. The $\mathrm{K}$ isotope variations we observe here are not likely due to terrestrial weathering, contamination, or alteration. As discussed in the 
Online Supplementary Material, these variations can not be attributed to the cosmicray radiation effect either. Therefore, these $\mathrm{K}$ isotope variations are more likely due to nebular or parent-body processes.

\subsection{Potassium isotope fractionation of carbonaceous chondrites}

For the CCs, there is a long-recognized trend of volatile depletion among the different chemical groups (Wasson and Chou, 1974; Wai and Wasson, 1977). As discussed in the Introduction and shown in Figure 1, this trend has the same monotonic depletion pattern starting from $\mathrm{CI}$ to $\mathrm{CM}, \mathrm{CO}, \mathrm{CV}, \mathrm{CR}$ and $\mathrm{CK}$ for all MVEs such as $\mathrm{Na}$, $\mathrm{K}, \mathrm{Rb}, \mathrm{Cu}$, and $\mathrm{Zn}$. The degrees of MVE depletion are mostly controlled by nebular volatilities (e.g., Lodders 2003) rather than by their chemical affinities (i.e., lithophile, siderophile, and chalcophile). Thus, this volatile depletion trend exhibited in the CCs has been attributed to solar nebular processes through either incomplete condensation (Wasson and Chou, 1974; Wai and Wasson, 1977; Humayun and Clayton, 1995; Cassen, 1996; Ciesla, 2008), or partial vaporization (Huss et al., 2003; Huss, 2004);

Previously, $\mathrm{K}$ isotopes have been used to distinguish between these two processes (Humayun and Clayton, 1995). As explained by Humayun and Clayton (1995), if the observed trend was caused by incomplete condensation (assuming near equilibrium conditions), we would expect no measurable $\mathrm{K}$ isotope fractionation between volatilerich CI and volatile-depleted CC groups. In contrast, partial vaporization involving Rayleigh distillation (a kinetic process) would enrich heavy $\mathrm{K}$ isotopes in depleted $\mathrm{CC}$ groups, for example, $\sim 25 \%$ enrichment for $\mathrm{CV}$ and $\sim 20 \%$ for $\mathrm{CM}$ relative to $\mathrm{CI}$ 
(Humayun and Clayton, 1995). The five CCs (one CI, Orgueil; one CM, Murchison; and three CV, Allende, Vigarano, and Leoville) previously studied by Humayun and Clayton (1995) showed no significant $\mathrm{K}$ isotope fractionation, thus they concluded that partial vaporization is inconsistent with the $\mathrm{K}$ isotopes and incomplete condensation from a hot solar nebula better accounts for the volatile depletion observed among the CC groups.

In this study, we analyzed $16 \mathrm{CCs}$ and observed a $\sim 2 \%$ variation among the $\mathrm{CC}$ samples with a typical $0.05 \%$ analytical uncertainty (see Figure 2). These new results agree with Humayun and Clayton (1995)'s study of the variation of K isotopes among the CCs. In their study, the difference in the $\mathrm{K}$ isotope composition between the highest $(1.5$ $\pm 0.5 \%$; CV3 Leoville) and lowest values $(-0.5 \pm 0.7 \%$; CV3 Allende) is $2.0 \pm 0.9 \%$. However, considering the error bars of 0.5-0.7 \%, their data was interpreted as isotopically homogenous among all chondrites. Here, we confirm the range of $\mathrm{K}$ isotopic variation first observed by Humayun and Clayton (1995), but suggest that these variations among the CCs are indeed resolvable. Our data also agree with Humayun and Clayton (1995) in that there is no well-defined trend of heavy K isotope enrichments with increasing degrees of elemental depletion (from $\mathrm{CI}$ to $\mathrm{CM}, \mathrm{CO}, \mathrm{CV}, \mathrm{CR}$ and $\mathrm{CK}$; see Figure 2). This lack of a clear trend in $\mathrm{K}$ isotopes among the CCs supports Humayun and Clayton (1995)'s conclusion that a single-stage partial vaporization process cannot generate both the $\mathrm{K}$ element and $\mathrm{K}$ isotopic variations exhibited among the $\mathrm{CC}$ groups. Alternatively, Young (2000) argued that diffusion-limited evaporation (e.g., evaporation of solid dust) would also suppress the $\mathrm{K}$ isotopic fractionation. In addition, evaporation experiments at higher pressures (e.g., 1 bar) also show much smaller $\mathrm{K}$ isotopic fractionation compared to evaporation experiments under low-pressure $\left(\sim 10^{-4}\right.$ bar $)$ 
nebular conditions (Yu et al., 2003; Richter et al., 2011). Thus, the suggestion that partial vaporization resulted in the volatile depletion trend exhibited in the CCs cannot be entirely ruled out.

Although there is no trend or correlation between $\mathrm{K}$ isotope compositions and $\mathrm{K}$ concentrations (or $\mathrm{K} / \mathrm{U}, \mathrm{K} / \mathrm{Al}$ ratios) among $\mathrm{CCs}$ (this is also true for $\mathrm{OCs}$ ), we note that there seems to be a rough inverse correlation when all chondrite groups (CCs + OCs) are considered together (see Figure 4). This rough inverse correlation clearly extends from the CCs to the OCs, and the correlation coefficients $\left(\mathrm{r}^{2}\right)$ are $0.453(\mathrm{~K} / \mathrm{U}), 0.586(\mathrm{~K} / \mathrm{Al})$, and $0.615([\mathrm{~K}])$. One could argue that the correlations with the $\mathrm{K} / \mathrm{U}$ and $\mathrm{K} / \mathrm{Al}$ ratios are due to changes in the abundances of the refractories ( $\mathrm{U}$ and $\mathrm{Al})$ in the chondrites. However, the absolute concentrations of $\mathrm{K}$ also show an inverse correlation with $\mathrm{K}$ isotopic composition (Figure 4c). Because our findings particularly highlight the larger $\delta^{41} \mathrm{~K}$ variations among meteorites within the same chemical groups rather than the variations between the average compositions of the different chondrite groups (see Figure 2), the correlation is largely driven by the clear differences in the isotopic compositions of the CCs (on average heavier than BSE) compared to the OCs (on average lighter than BSE). This $\mathrm{K}$ isotope dichotomy between the CCs and the OCs will be discussed in detail in Section 4.5.

The members of each $\mathrm{CC}$ group exhibit a large range of $\mathrm{K}$ isotopic compositions ( $1 \%$; for example, CM, CO, and CV see Figure 2) regardless of their degree of volatile depletion relative to CI. These intra-group variations are a significant reason for why a clear, well-defined trend is not discernable. Since $\mathrm{K}$ is fluid-mobile and moderately volatile, it is susceptible to modification in the parent bodies and heterogeneity could be 
introduced by the redistribution of $\mathrm{K}$. Thus, the range in $\mathrm{K}$ isotope fractionations within a meteorite group observed here might be the result of parent-body processes such as aqueous alteration, thermal metamorphism, and impact vaporization that overprinted any well-defined volatile element fractionations stemming from nebular processes recorded in the chondrite components that accreted to the different chondrite parent bodies.

Aqueous alteration and thermal metamorphism: Petrological types (1-6) of chondrites are commonly used as a general indicator for the degree of aqueous alteration and thermal metamorphism, where Type 3 represents the most primitive (unequilibrated) type. From Type 2 to 1 , the degree of aqueous alteration increases; while from Type 3.0 to 6 , the degree of thermal metamorphism increases. Figure 5a plots the $\mathrm{K}$ isotopes of the bulk CCs versus their petrological types. We find that the average $\mathrm{K}$ isotope compositions of petrologic types are not significantly different from each other, which is consistent with a closed-system and isochemical modification (Kerridge et al., 1979; McSween, 1979; Bland et al., 2009). As shown in Figure 5a, Type 3 CCs exhibit the largest variations in $\mathrm{K}$ isotopic compositions while, with increasing aqueous alteration (12) and thermal metamorphism (4-5), the $\mathrm{K}$ isotopes of different meteorites in the same chemical group become less dispersed. It appears both aqueous alteration and thermal metamorphism in the parent bodies have affected and likely homogenized the initial $\mathrm{K}$ isotopic compositions inherited from the components in the solar nebula that eventually accreted into the meteorite parent bodies (as shown in petrologic Type 3). However, this observation needs to be further confirmed with a larger dataset for each chemical group since currently the number of measured samples is limited (due to sample availability). 
Impact vaporization: Another possible source of isotopic fractionation is impact vaporization (e.g., Hin et al. 2017; Housley 1979; Moynier et al. 2011). Impact generated melting and vaporization have been invoked to explain the losses of the more volatile MVEs, $\mathrm{Cu}$ and $\mathrm{Zn}$, and associated isotopic fractionations (Moynier et al., 2009; Moynier et al., 2010a; Moynier et al., 2010b). The shock degrees of meteorites are indicative of the strength of the impact events on the parent body asteroids (see Table 1). Although the evaluation of the shock levels experienced by the CCs used in this study is very limited, we can examine the shock effect on $\mathrm{K}$ isotopes in the OCs (see Section 4.3). There is no correlation between the shock degrees and $\mathrm{K}$ isotopes for samples from the same chemical groups and petrological types (see Table 1). In general, the heterogeneity of the $\mathrm{K}$ isotopic compositions within a chondrite group does not seem to be the result of different degrees of impact vaporization. Nevertheless, we need to note that GRA 06100 does show evidence of shock metamorphism and subsequent shock-induced hydrothermal alteration (Abreu and Bullock, 2013). As shown in Table 1, the two chips of GRA 06100 show significantly different $\mathrm{K}$ isotope compositions $(0.16 \pm 0.03 \%$ vs. $0.70 \pm 0.02 \%$ ). Although the estimated peak temperature of shock metamorphism ( $\sim 60{ }^{\circ} \mathrm{C}$; Abreu and Bullock, 2013) is too low to be able to drive off the MVEs from the CR parent body, the shock-induced hydrothermal alteration could have fractionated $\mathrm{K}$ isotopes (Parendo et al., 2017; Li et al., 2019), which may explain the heterogeneity seen in the $\mathrm{K}$ isotopes of the two chips of GRA 06100.

It seems that parent body processing cannot explain the major $\mathrm{K}$ isotopic variations observed here, e.g., Type $3 \mathrm{CCs}$ show the largest $\mathrm{K}$ isotopic variations (see Figure 2). While parent-body processes may have equilibrated the $\mathrm{K}$ isotopes and reduced the 
variability (see Figure 5a), pre-accretionary processes likely played a major role in shaping the K isotope fractionation observed here. Recently, Alexander (2019) proposed a quantitative model that has successfully explained the elemental and isotopic fractionations among CCs. Here we apply this model to K isotopes.

Four-component-mixing model for $K$ isotopes: Alexander (2019) proposed that variable mixing of the same four components can reproduce the bulk elemental compositions and isotopic anomalies of the six $\mathrm{CC}$ groups $(\mathrm{CI}, \mathrm{CM}, \mathrm{CO}, \mathrm{CV}, \mathrm{CR}$ and CK). The four components are chondrules, refractory inclusions, matrix, and water. The model predicts the mass fractions of each component for the six $\mathrm{CC}$ groups (Table 5 in Alexander 2019) and estimates the end-member composition of each component (Table 6 in Alexander 2019). The model data can reconstruct the bulk K elemental compositions for the six $\mathrm{CC}$ groups (see Figure 6a). Here, we use our results to assign $\mathrm{K}$ isotopic compositions to each end-member component and to reconstruct the $\mathrm{K}$ isotopic compositions of the six CC groups (see Figure 6b). We take the $\mathrm{K}$ isotopic composition of a CI chondrite $(-0.53 \pm 0.11 \%$; Wang and Jacobsen $2016 \mathrm{a})$ as the composition of the matrix component. For the refractory inclusions and water components, there is no $\mathrm{K}$ isotopic composition assigned since these two components do not (nominally) contain $\mathrm{K}$ (see Table 6 in Alexander 2019). For the $\mathrm{K}$ isotopic composition of the chondrule component we have estimated a range of $-0.282 \%$ to $2.076 \%$ based on both theoretical and empirical considerations as explained below.

The measurements of $\mathrm{K}$ isotope compositions of individual chondrules have been conducted in situ using Secondary Ion Mass Spectrometry (SIMS) on Type 3 chondrites and show large variability (Alexander et al., 2000; Alexander and Grossman, 2005). Due 
to the isobar interferences and the matrix effect associated with the SIMS technique, the large variability was (at least partially) attributed to analytical artifacts (Alexander et al., 2000; Alexander and Grossman, 2005). However, chondrules from Type 3.0 chondrites (with little parent-body alteration) show a $\mathrm{K}$ depletion that is correlated with chondrule mass/size (Hewins et al., 1997) with larger chondrules showing higher depletions in K. This was attributed to more $\mathrm{K}$ volatilization during chondrule melting. We thus predict that larger chondrules are enriched in heavier $\mathrm{K}$ isotopes because volatile loss would enrich heavier $\mathrm{K}$ isotopes in the residual melt, as demonstrated by laboratory experiments (Yu et al., 2003; Richter et al., 2011). This isotope fractionation mechanism of evaporation during chondrule formation has been previously used to interpret the $\mathrm{Fe}$ isotope fractionation among individual chondrules from $\mathrm{CM}, \mathrm{CV}$ and ordinary chondrites (Mullane et al., 2005; Needham et al., 2009; Hezel et al., 2010; Hezel et al., 2018b). With the evidence in both observation and experiments discussed above, we would expect the chondrule component in the mixing model to be enriched in heavier $\mathrm{K}$ isotopes during chondrule formation events. As shown in the vaporization experiments (Yu et al., 2003; Richter et al., 2011), $\mathrm{K}$ isotope fractionation (in low pressure and dust density nebular environments) is very sensitive to the degree of $\mathrm{K}$ loss. A few $\%$ loss would induce a large (a few \%o) $\mathrm{K}$ isotope fractionation. Following the Rayleigh distillation law and using the ideal Rayleigh fractionation factor (square root of 41/39) in vacuum (e.g., a typical nebular pressure $\sim 10^{-4}$ bar), we estimated a range of $\mathrm{K}$ isotope compositions for the possible chondrule component as from $-0.282 \%$ to $2.076 \%$ depending on the fraction loss of K (from $1 \%$ to $10 \%$; labeled in Figure $6 \mathrm{~b}$ ) during chondrule formation. 
The maximum $10 \%$ loss of $\mathrm{K}$ during chondrule formation is constrained by the $\mathrm{Na}$ content in chondrules (Alexander et al., 2008). The estimated range of $\mathrm{K}$ isotopes among chondrules in this mixing model is consistent with the range (a few \%) measured in individual chondrules (Alexander et al., 2000; Alexander and Grossman, 2005).

We want to note that the loss of volatiles during the chondrule formation is insignificant (typically within a few \%; up to $10 \%$ ), which is consistent with Alexander (2019)'s model. Alexander (2019) proposed that the chondrule precursor had already lost MVEs prior to chondrule formation (melting and evaporation) as shown in the Fig. 14 in Alexander (2019) most likely through incomplete condensation (Wai and Wasson 1977; Wasson and Chou 1974), where no K isotopic fractionation is expected (Humayun and Clayton, 1995). The MVE depletion likely predated the chondrule formation events based on two constraints. 1) The abundances of MVEs in the chondrule component correlate well with their predicted $50 \%$ condensation temperatures (Wai and Wasson 1977; Wasson and Chou 1974). Therefore, volitalization during chondrule formation cannot be a dominant process for the MVE depletion as it would lead to a poor correlation between MVEs contents and their predicted $50 \%$ condensation temperatures. 2) The K isotopic compositions of chondrules would otherwise show much more extreme variaibility (up to $100 \%$; Humayun and Clayton (1995), which has not been observed (Alexander et al., 2000; Alexander and Grossman, 2005).

As explained above, we have applied the four-component mixing model from Alexander (2019) to K isotopes. Figure $\mathbf{6} \mathbf{b}$ shows that the model result in general agrees well with the measurements. For example, as shown in Figure $6 \mathrm{~b}, \mathrm{CR}$ chondrites show the heaviest $\mathrm{K}$ isotope compositions. Hezel et al. (2018a) recently compiled the median $\mathrm{K}$ 
elemental compositions of bulk chondrules from each chondrite group, and CR chondrules have the lowest $\mathrm{K}$ concentration, which is consistent with our model prediction (i.e., more $\mathrm{K}$ depletion results in higher $\mathrm{K}$ isotopic fractionation; see Figure 6b). The $\mathrm{K}$ isotopes of the different groups of CCs can be explained to the first order by the percentages of chondrule and matrix components, and to the second order, by the variation of chondrule sizes (corresponding to the different degree of $\mathrm{K}$ loss during chondrule formation; Hewins et al. 1997). It has been shown that chondrule sizes and $\mathrm{K}$ concentrations vary significantly between different groups of chondrites (Rubin, 2000; Jones, 2012; Hezel et al., 2018a). Regardless of whether the chondrule size distributions in the different $\mathrm{CC}$ groups were caused by physical size-sorting in turbulent nebula (e.g., Cuzzi et al. 2000) or due to repeated melting in different nebular environments (Rubin, 2010), the $\mathrm{K}$ isotopes of chondrules were likely fractionationed during their initial melting or remelting.

We note that chondrule sizes (or the degree of the loss of $\mathrm{K}$ during chondrule formation) also vary within the same meteorite (e.g., Rubin 1989), so some of the scattering of $\mathrm{K}$ isotopes in this study may also be due to the smaller sample sizes $(\sim 100$ $\mathrm{mg}$ ) where larger chondrules (up to $10 \mathrm{mg}$ each), or a lack there of, may skew the $\mathrm{K}$ isotope data of the bulk meteorites analyzed here. This could also explain some of the observed heterogeneity seen between different fragments of the same meteorite (see Table 1).

There is one outlier (CV3 LAR 12002) that cannot be explained by this mixing model. We analyzed two fragments of this meteorite independently and the results are similar $(-1.45 \pm 0.04 \%$ vs. $-1.54 \pm 0.03 \%$ ). This sample is distinct from the other two 
CV3 chondrites (Allende and GRA 06101), which are similar to each other and agree with the model. LAR 12002 is also an outlier among all $17 \mathrm{CCs}$, in that is the only CC that shows a $\mathrm{K}$ isotope composition that is significantly lower than the BSE value ( $\sim-0.5$ \%; see Figure 2). All other CCs have $\mathrm{K}$ isotope compositions that are similar to or higher than the BSE value (see Figure 2). Currently, no detailed study of this sample has been conducted, so it is possible that the K isotopic value of LAR 12002 has been altered by terrestrial weathering and/or contamination. For example, although GRA 06101 has been assigned the weathering grade $\mathrm{A} / \mathrm{B}$, abundant white greenish-blue evaporites were found on the surface of this sample (Satterwhite, 2013). Previous studies of other Antarctic meteorites have shown that these evaporites contain K (Gooding, 1981; Velbel et al., 1991). Nevertheless, it is unknown whether something such as these K-bearing evaporites affected the K isotope composition of LAR 12002, so further study is needed to understand its unique $\mathrm{K}$ isotope composition. As of now, we treat it as an outlier among the $\mathrm{CCs}$ due to its possible $\mathrm{K}$ isotopic fractionation during terrestrial weathering.

In summary, the $\mathrm{K}$ isotope fractionation observed in the $\mathrm{CCs}$ can be explained by a combination of both nebular and parent-body processes. The parent-body modification (aqueous and thermal alteration) tends to reduce the $\mathrm{K}$ isotope variation shown in Type 3 chondrites. The main pattern of $\mathrm{K}$ isotope variation among all $\mathrm{CC}$ groups, however, can generally be explained with the four-component mixing model (Alexander, 2019). While Alexander (2019)'s model assumed only one set (average) of values for the elemental compositions and isotopic anomalies of the chondrule component, here, we require a range of $\mathrm{K}$ isotope compositions for the chondrule component in order to explain the variation of $\mathrm{K}$ isotopes observed in the bulk CCs. This requirement is consistent with the 
the chondrule size distributions observed in the different chemical groups of chondrites (Rubin, 2000; Jones, 2012) and the chondrule size correlation with K concentration/isotopes (Hewins et al., 1997). As such, this suggests the importance of physical size-sorting of particles in the nebula on the chemical and isotopic fractionation of different groups of CCs in addition to the mixing of different chemical and isotopic reservoirs (e.g., Alexander 2019).

\subsection{Potassium isotope fractionation of ordinary chondrites}

The OCs in this study include all three chemical groups, and petrological types, as well as a wide range of shock levels, cosmic-ray exposure ages, both falls and finds, and extents of terrestrial weathering. As discussed in Section 4.1 and the Online Supplementary Material (see Figure 3 and Supplementary Figure S1), we observed no $\mathrm{K}$ isotopic variation correlating with either falls or finds, degree of terrestrial weathering, or cosmic-ray exposure ages. Below, we discuss whether chemical group, petrological type or shock level resulted in any measurable effect on the $\mathrm{K}$ isotopic compositions of OCs.

Chemical groups: Unlike the CCs, there is no obvious trend of lithophile MVE depletion versus their nebular volatilities among the three chemical groups (see Figure 1). Compared to the CCs, the three OC chemical groups, in general, have similar abundances of MVEs (see Figure 1). In this study, we show that the $\mathrm{K}$ isotopic composition of the three chemical groups also have similar and comparable ranges (see Figure 2). The 28 samples studied here cover all three chemical groups, with 10 samples 
belonging to the $\mathrm{H}$ group, 10 belonging to the $\mathrm{L}$ group, and 8 belonging to the LL group. The three different chemical groups of H, L, and LL represent at least three different parent bodies (Krot et al., 2014). Although all three groups exhibit a similar ( 1\%o) range of $\mathrm{K}$ isotope compositions (from $-1.5 \%$ to $-0.5 \%$ ) and all generally have lighter $\mathrm{K}$ isotope compositions than the $\operatorname{BSE}(-0.5 \%)$, the $\mathrm{H}$ group has two samples that are significantly enriched in heavy $\mathrm{K}$ isotopes compared to the BSE and other OCs (see Figure 2b). These two samples are RKPA 78004 (H4, $0.00 \pm 0.03 \%$ ) and PRE 95400 $(\mathrm{H} 5,0.07 \pm 0.03 \%$ and $0.04 \pm 0.05 \%$ for the two fragments measured here). Excluding these two samples, the average $\mathrm{K}$ isotope composition of the $\mathrm{H}$ group is not significantly different from those of the L and LL groups. Thus, currently there appears to be no bulk $\mathrm{K}$ isotopic differences between the $\mathrm{H}, \mathrm{L}$ and LL parent bodies.

Thermal metamorphism: Petrologic Types 4 to 6 represent samples that have experienced increasing degrees of thermal metamorphism and higher degrees of chemical equilibration in their parent bodies. Figure $\mathbf{5}$ (b, c and d) shows $\mathrm{K}$ isotopes versus the petrologic types for the $\mathrm{H}, \mathrm{L}$ and LL groups. We found no apparent correlation between the $\mathrm{K}$ isotopes and petrologic types within each group. The Type 4 and $5 \mathrm{H}$ groups have the largest variations; however, again this is simply due to the two outliers of RKPA 78004 (H4) and PRE 95400 (H5) (see Figure 5b). Excluding these two outliers, the range of $\mathrm{K}$ isotope compositions of each petrological type from each chemical group generally overlap with each other and show no consistent trends.

As discussed in Section 4.2, large (a few \%o) $\mathrm{K}$ isotopic fractionations have been observed in chondrules, so consequently, the variation of $\mathrm{K}$ isotopes in "bulk" chondrites to some degree depends on the chondrule modal abundances in the specific fragments of 
the meteorites studied (e.g., different chips of the same meteorites; see Table 2). Type 3 OCs would thus be expected to have the largest variation/heterogeneity in $\mathrm{K}$ isotopes. With increasing thermal metamorphism, $\mathrm{K}$ becomes more mobile and chondrules would exchange $\mathrm{K}$ with other chondrules and the matrix (Grossman and Brearley, 2005). The thermal metamorphism in parent bodies would be expected to equilibrate the $\mathrm{K}$ isotopes between different components (i.e., chondrule-chondrule and chondrule-matrix), which have very different initial $\mathrm{K}$ isotope compositions (Alexander et al., 2000; Alexander and Grossman, 2005). Thus, with increasing petrologic type, OCs would be expected to have less variation in $\mathrm{K}$ isotopes than the unequilibrated Type 3s. Nevertheless, due to the limited number of samples analyzed for $\mathrm{K}$ isotopes for each petrological type, it is still not clear whether the expected $\mathrm{K}$ isotope homogenization occurred in OCs or not.

Aqueous alteration and metasomatism: Although the petrological type (3-6) usually assigned to OCs does not indicate the existence and degree of aqueous alteration like the petrological type (1-2), evidence of aqueous alteration and metasomatism has been widely observed in both equilibrated and unequilibrated OCs (e.g., Brearley, 2007; Lewis and Jones, 2016; Lewis and Jones, 2019). For example, Hutchison et al. (1987) and Alexander et al. (1989) reported the presence of smectite and calcite in Type 3 OCs, which provided the first direct evidence of in-situ aqueous alteration. In addition, Grossman et al. (2000) described textually distinct and alkli-depleted chondrules within OCs of all petrological types and interpreted these as water bleached chondrules. As another example, aqueous fluid inclusions in alkali chlorides (halide $\mathrm{NaCl}$ and sylvite $\mathrm{KCl}$ ) were found in the matrix of the H5 OC Monahans (Zolensky et al., 1999). Potassium is soluble, and it has recently been reported that dissolved $\mathrm{K}$ in solution (e.g., 
river water) is usually enriched in heavier isotopes when compared to the leached residue (Li et al., 2019). Thus, aqueous alteration in parent bodies could potentially change the pre-accretionary $\mathrm{K}$ isotopic compositions and fractionate $\mathrm{K}$ isotopes between different components of chondrites (e.g., bleached chondrules vs. matrix containing precipitated salts, as well as clay minerals and hydrothermal feldspars). We would expect the bleached chondrules to be enriched in the lighter $\mathrm{K}$ isotope, while the $\mathrm{K}$ salts (precipitated from the bleaching water; Rubin et al. 2002; Zolensky et al. 1999) in the matrix would be enriched in the heavier $\mathrm{K}$ isotope. However, such a prediction cannot be confirmed with the bulk analyses of OCs and so would need to be tested with future insitu studies.

The aqueous alteration in the OCs has been found to be decoupled from thermal metamorphism (Grossman et al., 2000). Therefore, petrological type (3-6) is not a good indicator for the degree of aqueous alteration in OCs. Currently there is no adequate index for such a purpose. Thus, it is challenging to evaluate aqueous alteration effects on the $\mathrm{K}$ isotopes of OCs even in a qualitative fashion. For example, Grossman et al. (2000) found that L and LL OCs contain more bleached chondrules than H OCs, meaning L and LL OCs have likely been more aqueously altered than H OCs. However, as shown in Figure 5, we do not observe any significant difference in $\mathrm{K}$ isotopes between $\mathrm{H}$ and $\mathrm{L} / \mathrm{LL}$ OCs. We should note, however, that although $\mathrm{K}$ is mobile during aqueous alteration and the $\mathrm{K}$ can be leached out from chondrules and deposited in the matrix, large and representative bulk chondrites should be treated as a closed-system for $\mathrm{K}$ (not for $\mathrm{H}_{2} \mathrm{O}$ as it could be lost from the parent body due to thermal metamorphism) (Grossman et al., 2000). This might be the reason why no systematic $\mathrm{K}$ isotopic differences are observed 
between bulk $\mathrm{H}$ and L/LL OCs. Nevertheless, aqueous alteration, in principle, would be a possible mechanism for generating $\mathrm{K}$ isotope fractionation and heterogeneity in the parent bodies of the OCs. The two outliers, RKPA 78004 (H4) and PRE 95400 (H5), could possibly have been affected by aqueous alteration, which would make the fragments studied here not representative of the bulks. However, no detailed studies of aqueous alteration in these two samples are currently available.

Impact vaporization: As previously discussed in Section 4.2, impact vaporization is another mechanism that is known to fractionate the isotopes of MVEs such as $\mathrm{Zn}$ and $\mathrm{Cu}$ (e.g., Moynier et al., 2009; Frederic Moynier et al., 2010). However, for OC samples from the same chemical groups and petrological types, we did not observe any correlation between shock stage and $\mathrm{K}$ isotope composition (see Table 1). For example, Bjurböle (shock level S1) and ALH 85033 (shock level S6) are both L4 OCs which experienced very different degrees of shock yet they have indistinguishable $\mathrm{K}$ isotopic compositions $(-0.83 \pm 0.05 \%$ vs. $-0.92 \pm 0.08 \%$ \%). ALH 85017 (shock level S6) and ALHA 76001 (shock level S3) are another example, as both are L6 finds with different degrees of shock but show very similar K isotope compositions $(-0.74 \pm 0.03 \%$ vs. $-0.82 \pm 0.04 \%$ ). This observation is consistent with a recent thermochemical calculation that shows, in general, a lower volatility of $\mathrm{K}$ compared to other MVEs such as $\mathrm{Zn}$ and $\mathrm{Cu}$ during impact vaporization (Jiang et al., 2019). Their observation on the $\mathrm{K}$ isotopes of tektites (impactgenerated melts formed on Earth) shows a similar trend to what is seen in OCs here, with no $\mathrm{K}$ isotope fractionation compared to the source rocks (in this case of tektites) (Jiang et al., 2019), in constrast to other MVE isotopes such as $\mathrm{Zn}$ and $\mathrm{Cu}$, which show significant fractionation (Moynier et al., 2009; Moynier et al., 2010a; Moynier et al., 2010b). Thus, 
unlike $\mathrm{Zn}$ and $\mathrm{Cu}$ isotopes, the $\mathrm{K}$ isotope variation among OCs observed here cannot be explained as the result of impact vaporization.

In summary, the $\mathrm{K}$ isotope fractionation observed in OCs can be generated by both nebular and parent-body processes. Nevertheless, there are no significant trends or differences between the different OC chemical groups or petrologic types and there are often larger variations within the same groups than there is between groups. Consequently, we attribute the full range of $\mathrm{K}$ isotopic compositions observed in the OCs

to the combined effects of 1) $\mathrm{K}$ isotope fractionation during chondrule formation as suggested by measurments of individual chondrules from OCs (Alexander et al., 2000; Alexander and Grossman, 2005); 2) mixing of different sized chondrules; 3) chondrules and matrix propotions; 4) parent-body aqueous and thermal alteration; and 5) sampling bias.

\subsection{Comparison of $K$ isotopes with isotopes of other moderately volatile elements}

\section{$(\mathrm{Cu}, \mathrm{Zn}$, and $\mathrm{Rb})$ in chondrites}

Potassium is a moderately volatile element with a $50 \%$ condensation temperature of $1006 \mathrm{~K}$ (Lodders, 2003), which is similar to the $50 \%$ condensation temperatures of $\mathrm{Cu}$ $(1037 \mathrm{~K})$. Zinc $(726 \mathrm{~K})$ and $\mathrm{Rb}(800 \mathrm{~K})$ have $50 \%$ condensation temperatures that are lower than K; however, they all belong to the MVE group and are often compared to each other. Here, we compare our chondrite $\mathrm{K}$ isotope dataset with previously published chondrite isotope data for these other MVEs $(\mathrm{Cu}, \mathrm{Zn}$, and $\mathrm{Rb})$. 
Among the three MVEs listed above, $\mathrm{Zn}$ isotopes are the most extensively studied, with the $\mathrm{Zn}$ isotopes of CCs and OCs having been measured by Luck et al. (2005), Moynier et al. (2007), Barrat et al. (2012), and Pringle et al. (2017). These studies found a positive correlation between $\mathrm{Zn}$ isotopes and $\mathrm{Zn}$ concentrations among the $\mathrm{CCs}$, where $\mathrm{CI}$ chondrites have the highest $\mathrm{Zn}$ concentration and the heaviest $\mathrm{Zn}$ isotopic composition. This positive correlation among the different $\mathrm{CC}$ chemical groups is the opposite to what was expected for $\mathrm{Zn}$ isotope fractionation via a simple kinetic evaporation. Thus, Luck et al. (2005) and Pringle et al. (2017) interpreted this positive trend as the mixing between two isotopically distinct reservoirs (high $\mathrm{Zn}$ and heavier $\mathrm{Zn}$ isotope reservoir vs. low $\mathrm{Zn}$ and lighter $\mathrm{Zn}$ isotope reservoir). As for OCs, all three groups show similar ranges of $\mathrm{Zn}$ isotope variation and, in general, are enriched in lighter $\mathrm{Zn}$ isotopes in comparison CCs (Luck et al., 2005). As shown in Figure 4c, there is no clear trend between $\mathrm{K}$ isotopes and $\mathrm{K}$ concentrations. As discussed in Section 4.2, for the CCs our $\mathrm{K}$ isotopes and $\mathrm{K}$ concentrations can be satisfactorily explained by Alexander (2019)'s four-component-mixing (chondrule, refractory inclusion, matrix and water) model. However, for simplicity and ease of fitting Alexander (2019)'s model assumes a complete loss of $\mathrm{Zn}$ from the chondrule component and no $\mathrm{Zn}$ in the refractory inclusions or water, so all the $\mathrm{Zn}$ would have to come from the single source/reservoir: the matrix. This would cause all CCs to have the same $\mathrm{Zn}$ isotope composition regardless of their chemical groups and Zn concentrations, which Alexander (2019) acknowledged is not consistent with the observations (Luck et al., 2005; Moynier et al., 2007; Pringle et al., 2017). As such, the $\mathrm{Zn}$ isotopes of chondrites cannot be reconciled with Alexander 
(2019)'s model and $\mathrm{Zn}$ isotopes also appear to be decoupled from the $\mathrm{K}$ isotope fractionation of chondrites seen in this study (see Figure 7a).

The $\mathrm{Cu}$ isotopes of the CCs and OCs have been analyzed by Luck et al. (2003), Moynier et al. (2007) and Barrat et al. (2012). Generally, the $\mathrm{Cu}$ isotope compositions of the CCs co-vary with $\mathrm{Zn}$ isotopes and have a positive correlation with $\mathrm{Cu}$ concentrations, where $\mathrm{CI}$ chondrites have the highest $\mathrm{Cu}$ concentration and the heaviest $\mathrm{Cu}$ isotope composition. In addition, Luck et al. (2003) identified a correlation between $\mathrm{Cu}$ isotopes and mass-independent $\mathrm{O}$ isotopes $\left(\Delta^{17} \mathrm{O}\right)$, which suggests that the $\mathrm{Cu}$ isotope compositions of the $\mathrm{CCs}$ were also created by the mixing of two distinct $\mathrm{Cu}$ isotope reservoirs in the solar nebula (high $\mathrm{Cu}$ and heavier $\mathrm{Cu}$ isotope reservoir vs. low $\mathrm{Cu}$ and lighter $\mathrm{Cu}$ isotope reservoir). For the $\mathrm{OCs}$, the $\mathrm{Cu}$ isotopes fall on a different mixing line and hint that there is at least one more reservoir that is distinct from the two which make up the CCs. According to Alexander (2019)'s model, the $\mathrm{Cu}$ concentrations of the CCs can be derived from mixing the chondrule component with the matrix component since there is no $\mathrm{Cu}$ in the refractory inclusion and water components. In order to match the observed $\mathrm{Cu}$ isotopic compositions of the CCs (Luck et al., 2003; Moynier et al., 2007; Barrat et al., 2012), the matrix component needs to be enriched in the heaviest $\mathrm{Cu}$ isotope composition while the chondrule component in the lightest isotope composition. This is the opposite to what we expect for $\mathrm{K}$ isotopes in the chondrule and matrix components, where chondrules are enriched in heavier $\mathrm{K}$ isotopes due to the Rayleigh fractionation via vaporization during the chondrule formation (Yu et al., 2003; Richter et al., 2011). However, there is a possible way to reconcile the differences between the $\mathrm{Cu}$ and $\mathrm{K}$ isotopes. Copper has only two stable isotopes, thus, we cannot distinguish the $\mathrm{Cu}$ isotope 
fractionation caused by mass-dependent processes (e.g., evaporation/condensation) from the variations caused by radioactive decay. If the decay of ${ }^{63} \mathrm{Ni}$ (instead of massdependent processes) is dominating the $\mathrm{Cu}$ isotope composition, the $\mathrm{Cu}$ isotopes of the CCs and OCs (see details in Luck et al., 2003; Moynier et al., 2007; Barrat et al., 2012) can be consistent with the model of Alexander (2019) and be decoupled from the K isotopes at the same time (see Figure $7 \mathrm{~b}$ ). However, whether $\mathrm{Cu}$ isotopic variations among chondrites are due to the decay of ${ }^{63} \mathrm{Ni}$ still requires further investigation.

The $\mathrm{Rb}$ isotopes of chondrites are the least studied and have been only reported by Pringle and Moynier (2017). They found a similar trend to the one observed for the $\mathrm{Zn}$ and $\mathrm{Cu}$ isotopes of the $\mathrm{CCs}$. Again, there is a positive correlation between $\mathrm{Rb}$ isotopes and $\mathrm{Rb}$ concentrations among the $\mathrm{CCs}$, whereas the $\mathrm{CI}$ chondrites have the highest $\mathrm{Rb}$ concentration and the heaviest $\mathrm{Rb}$ isotope composition (Pringle and Moynier, 2017). Similar to $\mathrm{Zn}$ and $\mathrm{Cu}$ isotopes, Pringle and Moynier (2017) interpreted this positive trend as the mixing between two isotopically distinct reservoirs (high $\mathrm{Rb}$ and heavier $\mathrm{Rb}$ isotope reservoir vs. low $\mathrm{Rb}$ and lighter $\mathrm{Rb}$ isotope reservoir). Only one $\mathrm{OC}$ has been analyzed, and its $\mathrm{Rb}$ isotope composition is lighter than those of all CCs. Despite the close chemical similarity between $\mathrm{Rb}$ and $\mathrm{K}$, the $\mathrm{Rb}$ isotopes of chondrites cannot be reconciled with the $\mathrm{K}$ isotopes (see Figure 7c). Therefore, future experimental studies are urgently required to better our understanding of the different geochemical and cosmochemical behaviors of MVEs during nebular and/or parent-body processes. 


\subsection{The $\mathrm{K}$ isotope comparison between carbonaceous, ordinary and enstatite chondrites}

The major and most intriguing observation of this study on $16 \mathrm{CCs}$ and $28 \mathrm{OCs}$ is that although both CCs and OCs overlap with the BSE value, most CCs have heavier K isotopes relative to the BSE while that majority of OCs have lighter $\mathrm{K}$ isotopes. This observation suggests a dichotomy in $\mathrm{K}$ isotopes between the CCs and OCs. A dichotomy between the CCs and OCs can be also found in the mass-dependent isotope systems of other MVEs, such as Cu, Zn and Rb (Luck et al., 2003; Luck et al., 2005; Moynier et al., 2007; Barrat et al., 2012; Wang and Jacobsen, 2016b; Pringle et al., 2017; Pringle and Moynier, 2017). In each case, although with some overlap, the CCs are typically enriched in the heavier isotopes relative to the OCs. In contrast, $\mathrm{Li}$ is the least volatile element among MVEs (e.g., Sossi and Fegley, 2018) and there is no measurable difference between CCs and OCs in Li isotopes (Pogge von Strandmann et al., 2011). Similarly, for the mass-dependent isotope systems of non-volatile elements (50\% condensation temperatures higher than Li), CCs and OCs also show no resolvable difference, such as Mg (e.g., Teng et al., 2010; Schiller et al., 2010; Bourdon et al., 2010; Pogge von Strandmann et al., 2011; Hin et al., 2017), Si (e.g., Georg et al., 2007; Fitoussi et al., 2009; Armytage et al., 2011; Dauphas et al., 2015), Ca (e.g., Simon and DePaolo, 2010; Valdes et al., 2014; Huang and Jacobsen, 2017), Ti (e.g., Greber et al., 2017; Deng et al., 2018), V (e.g., Nielsen et al., 2014; Xue et al., 2018), and Fe (e.g., Craddock and Dauphas 2011; Poitrasson et al. 2004; Wang et al. 2013). The fact that only isotopes of elements more volatile than $\mathrm{Li}$ (e.g., $\mathrm{K}, \mathrm{Cu}, \mathrm{Zn}$ and $\mathrm{Rb}$ ) show a mass dependent dichotomy between the CCs and OCs is still intriguing. It is possible that the reservoirs or 
components of the OCs and CCs experienced different extents of evaporation/condensation processes or dust-gas separation that enriched heavier isotopes of MVEs in CCs relative to OCs. The $\mathrm{K}$ isotopic dichotomy, at least, cannot be simply explained by post-accretionary processes (e.g., aqueous and thermal alterations on parentbodies) as discussed in Sections 4.2 and 4.3.

We want to clarify that this dichotomy between OCs and CCs in K isotopes does not extend to all non-carbonaceous chondrites (NCs; OCs + enstatite chondrites + Rumuruti chondrites) versus CCs. If enstatite chondrites (ECs) are included there is no dichotomy in $\mathrm{K}$ isotopes, or $\mathrm{Cu}, \mathrm{Zn}$ and $\mathrm{Rb}$ isotopes, between the $\mathrm{NCs}$ and $\mathrm{CCs}$ (Moynier et al., 2007; Moynier et al., 2011; Pringle and Moynier, 2017; Zhao et al., 2019). As shown in Figure 8, although there is a clear separation between the probability distribution functions of $\mathrm{K}$ isotopes in the CCs and OCs, the ECs fall in the middle and overlap with both the CCs and OCs and cannot be distinguished from either. Although the data for the ECs are highly scattered, interestingly, among the CCs, OCs and ECs, ECs have the most similar $\mathrm{K}, \mathrm{Cu}, \mathrm{Zn}$ and Rb isotopes to the Earth (Moynier et al., 2007; Moynier et al., 2011; Pringle and Moynier, 2017; Zhao et al., 2019), which is to some degree surprising since the Earth is depleted in MVEs compared to ECs (see Figure 1). It is not known why the MVE isotopes were not fractionated during the process(es) that depleted the MVEs in Earth. Nevertheless, such (mass-dependent) isotopic similarity between the ECs and Earth in MVEs is consistent with the model suggesting that the ECs and Earth formed from the same precursor materials based on isotopic anomalies (e.g., Javoy, 1995; Javoy et al., 2010; Dauphas, 2017). 
Lastly, we want to note that the lack of a dichotomy between the NCs and CCs in MVEs isotopes is in contrast to the clear dichotomy between the NCs and CCs that is widely observed in elemental abundances (e.g., $\mathrm{Mg} / \mathrm{Si}$ vs. $\mathrm{Al} / \mathrm{Si}$ ) and in many massindependent isotope systems (Warren, 2011a; Warren, 2011b). Different from massindependent isotope systems, the mass-dependent isotope systems are not the most suitable to trace the sources/precursors since they can be fractionated by many physical and chemical processes, such as evaporation/condensation in the solar nebular environments or aqueous alteration/thermal metamorphism on the parent-body asteroids. 


\section{CONCLUSIONS}

In this study, we report the most complete and systematic $\mathrm{K}$ isotope study of 16 CCs and 28 OCs, covering the entire spectrum of chemical groups and petrological types. We observed up to $\sim 2 \%$ variations in the $\mathrm{K}$ isotopic composition of chondrites, which is consistent with the findings of Humayun and Clayton (1995). With the improved precision, we provide the best current estimate of $\mathrm{K}$ isotopic compositions for the $\mathrm{CCs}$ and OCs. The variation observed among the CCs and OCs can be explained by the combined effects of both solar nebular and parent-body processes.

We do not observe any significant correlations between the $\mathrm{K}$ isotopic compositions and $\mathrm{K}$ elemental concentrations (or elemental ratios such as $\mathrm{K} / \mathrm{U}, \mathrm{K} / \mathrm{Si}$ and $\mathrm{K} / \mathrm{Al}$ ). This rules out a single-stage partial vaporization process to account for both the $\mathrm{K}$ isotope variations found here, as well as the well-known progressive elemental depletion pattern of moderately volatile elements among CCs. Nevertheless, both the K isotope pattern demonstrated here and the MVE depletion pattern of CCs can be explained by the mixing model of Alexander (2019), with isotope fractionation during chondrule formation and chondrule size distribution among CCs playing an important role.

Although there are no clear correlations between $\mathrm{K}$ isotopes and petrological types for either the CCs or OCs, based on previous abundant petrological and geochemical evidence on $\mathrm{K}$ mobility during aqueous alteration and thermal metamorphism, we propose that parent-body alterations potentially fractionate the $\mathrm{K}$ isotope compositions of both the CCs and OCs. The simple scheme of petrological types (1-6) assigned to meteorites cannot precisely describe the K mobility and isotope fractionation. Parentbody alterations would not only have contributed to the variation between meteorites, but 
also to the heterogeneity within the same meteorites observed in this study. However, the bulk asteroids should remain a closed-system for $\mathrm{K}$ unlike some volatiles $\left(\mathrm{H}_{2} \mathrm{O}\right)$ which can be lost to space during a high degree of thermal metamorphism.

The most prominent observation of this study is the $\mathrm{K}$ isotopic difference between the CCs and OCs, which is consistent with observations seen by other mass-dependent isotope systems of MVEs. However, when ECs are combined with OCs as a combined $\mathrm{NC}$, there is no dichotomy observed between the them and CCs in any MVE isotope system, which is in contrast to the clear dichotomy observed in mass-independent isotope systems. 


\section{ACKNOWLEDGEMENTS}

We thank the Associate Editor Dr. Thorsten Kleine for prompt handling and editing of this manuscript. We also thank reviewers Dr. Conel Alexander and Dr. Haolan Tang as well as one anonymous reviewer for their thorough comments. We would like to thank Dr. Kevin Righter from NASA Johnson Space Center, and Dr. Philipp Heck from The Field Museum in Chicago for providing samples. We would also like to thank the McDonnell Center for the Space Sciences and WUSTL Office of Undergraduate Research for funding our research endeavors. Work by KL is supported in part by NSF AST 1517541. MKP has received funding from the European Union's Horizon 2020 research and innovation programme under the Marie Sklodowska-Curie grant agreement No 753276. YJ is supported by NSFC (Grant Nos. 41873076).

US Antarctic meteorite samples are recovered by the Antarctic Search for Meteorites (ANSMET) program, which has been funded by NSF and NASA, and characterized and curated by the Department of Mineral Sciences of the Smithsonian

Institution and Astromaterials Acquisition and Curation Office at NASA Johnson Space Center. 


\section{REFERENCES}

Abreu N. M. and Bullock E. S. (2013) Opaque assemblages in CR2 Graves Nunataks (GRA) 06100 as indicators of shock-driven hydrothermal alteration in the CR chondrite parent body. Meteorit. Planet. Sci. 48, 2406-2429.

Albarède F. (2009) Volatile accretion history of the terrestrial planets and dynamic implications. Nature 461, 1227-1233.

Alexander C. M. O’D. (2019) Quantitative models for the elemental and isotopic fractionations in chondrites: The carbonaceous chondrites. Geochim. Cosmochim. Acta.

Alexander C. M. O’D., Boss A. P. and Carlson R. W. (2001) The early evolution of the inner solar system: A meteoritic perspective. Science 293, 64-68.

Alexander C. M. O’D. and Grossman J. N. (2005) Alkali elemental and potassium isotopic compositions of Semarkona chondrules. Meteorit. Planet. Sci. 40, 541-556.

Alexander C. M. O’D., Grossman J. N., Ebel D. S. and Ciesla F. J. (2008) The formation conditions of chondrules and chondrites. Science 320, 1617-9.

Alexander C. M. O’D., Grossman J. N., Wang J., Zanda B., Bourot-Denise M. and Hewins R. H. (2000) The lack of potassium-isotopic fractionation in Bishunpur chondrules. Meteorit. Planet. Sci. 35, 859-868.

Alexander C. M. O'D, Barber D. . and Hutchison R. (1989) The microstructure of Semarkona and Bishunpur. Geochim. Cosmochim. Acta 53, 3045-3057.

Anders E. (1964) Origin, age, and composition of meteorites. Space Sci. Rev. 3, 583-714.

Armytage R. M. G., Georg R. B., Savage P. S., Williams H. M. and Halliday A. N. (2011) Silicon isotopes in meteorites and planetary core formation. Geochim. Cosmochim. Acta 75, 3662-3676.

Baadsgaard H., Campbell F. A., Folinsbee R. E. and Cumming G. L. (1961) The Bruderheim meteorite. J. Geophys. Res. 66, 3574-3577.

Barrat J. A., Zanda B., Moynier F., Bollinger C., Liorzou C. and Bayon G. (2012) Geochemistry of CI chondrites: Major and trace elements, and $\mathrm{Cu}$ and $\mathrm{Zn}$ Isotopes. Geochim. Cosmochim. Acta 83, 79-92.

Bischoff A., Schleiting M., Wieler R. and Patzek M. (2018) Brecciation among 2280 ordinary chondrites - Constraints on the evolution of their parent bodies. Geochim. Cosmochim. Acta 238, 516-541.

Bischoff A., Weber D., Clayton R. N., Faestermann T., Franchi I. A., Herpers U., Knie K., Korschinek G., Kubik P. W. and Mayeda T. K. (1998) Petrology, chemistry, and isotopic compositions of the lunar highland regolith breccia Dar al Gani 262. Meteorit. Planet. Sci. 33, 1243-1257.

Bland P. A., Jackson M. D., Coker R. F., Cohen B. A., Webber J. B. W., Lee M. R., Duffy C. M., Chater R. J., Ardakani M. G., McPhail D. S., McComb D. W. and Benedix G. K. (2009) Why aqueous alteration in asteroids was isochemical: High porosity $\neq$ high permeability. Earth Planet. Sci. Lett. 287, 559-568.

Bourdon B., Tipper E. T., Fitoussi C. and Stracke A. (2010) Chondritic Mg isotope composition of the Earth. Geochim. Cosmochim. Acta 74, 5069-5083.

Brearley A. J. (2007) Nebular versus Parent-body Processing. Volume 1 of Treatise on Geochemistry (Second Edition) (ed. A. M. Davis). pp. 309-334

Brearley A. J., Scott E. R. ., Keil K., Clayton R. N., Mayeda T. K., Boynton W. V and Hill D. H. (1989) Chemical, isotopic and mineralogical evidence for the origin of 
matrix in ordinary chondrites. Geochim. Cosmochim. Acta 53, 2081-2093.

Cassen P. (1996) Models for the fractionation of moderately volatile elements in the solar nebula. Meteorit. Planet. Sci. 31, 793-806.

Chen H., Tian Z., Tuller-Ross B., Korotev R. L. and Wang K. (2019) High-precision potassium isotopic analysis by MC-ICP-MS: An inter-laboratory comparison and refined K atomic weight. J. Anal. At. Spectrom. 34, 160-171.

Ciesla F. J. (2008) Radial transport in the solar nebula: Implications for moderately volatile element depletions in chondritic meteorites. Meteorit. Planet. Sci. 43, 639655.

Craddock P. R. and Dauphas N. (2011) Iron isotopic compositions of geological reference materials and chondrites. Geostand. Geoanalytical Res. 35, 101-123.

Crozaz G. and Wadhwa M. (2001) The terrestrial alteration of saharan shergottites dar al gani 476 and 489: a case study of weathering in a hot desert environment. Geochim. Cosmochim. Acta 65, 971-977.

Cuzzi J. N., Hogan R. C., Paque J. M. and Dobrovolskis A. R. (2000) Size-selective concentration of chondrules and other small particles in protoplanetary nebula turbulence. Astrophys. J. 546, 496-508.

Dauphas N. (2017) The isotopic nature of the Earth's accreting material through time. Nature 541, 521-524.

Dauphas N., Poitrasson F., Burkhardt C., Kobayashi H. and Kurosawa K. (2015) Planetary and meteoritic $\mathrm{Mg} / \mathrm{Si}$ and $\delta^{30} \mathrm{Si}$ variations inherited from solar nebula chemistry. Earth Planet. Sci. Lett. 427, 236-248.

Davis A. M. (2006) Volatile Evolution and Loss. In Meteorites and the Early Solar System II (eds. D. S. Lauretta and H. Y. McSween). University of Arizona Press, Tucson. pp. 295-307.

Day J. M. D. and Moynier F. (2014) Evaporative fractionation of volatile stable isotopes and their bearing on the origin of the Moon. Philos. Trans. A. Math. Phys. Eng. Sci. 372, 20130259.

Deng Z., Moynier F., van Zuilen K., Sossi P. A., Pringle E. A. and Chaussidon M. (2018) Lack of resolvable titanium stable isotopic variations in bulk chondrites. Geochim. Cosmochim. Acta 239, 409-419.

Easton A. J. and Elliott C. J. (1977) Analyses of some meteorites from the British Museum (Natural History) collection. Meteoritics 12, 409-416.

Endress M. and Bischoff A. (1993) Mineralogy, Degree of Brecciation, and Aqueous Alteration of CI Chondrites Orgueil, Ivuna, and Alais. Meteoritics 28, 345.

Fegley B., Jacobson N. S., Williams K. B., Plane J. M. C., Schaefer L. and Lodders K. (2016) Solubility of rock in steam atmospheres of planets. Astrophys. J. 824, 103.

Fitoussi C., Bourdon B., Kleine T., Oberli F. and Reynolds B. C. (2009) Si isotope systematics of meteorites and terrestrial peridotites: implications for $\mathrm{Mg} / \mathrm{Si}$ fractionation in the solar nebula and for Si in the Earth's core. Earth Planet. Sci. Lett. 287, 77-85.

Fulton C. R. and Rhodes J. M. (1984) The chemistry and origin of the ordinary chondrites: Implications from refractory-lithophile and siderophile elements. $J$. Geophys. Res. 89, B543.

Georg R. B., Halliday A. N., Schauble E. A. and Reynolds B. C. (2007) Silicon in the Earth's core. Nature 447, 1102-1106. 
Gooding J. L. (1981) Mineralogical aspects of terrestrial weathering effects in Allan Hills. Proc. 12th Lunar Planet. Sci. Conf. 12, 1105-1122.

Greber N. D., Dauphas N., Puchtel I. S., Hofmann B. A. and Arndt N. T. (2017) Titanium stable isotopic variations in chondrites, achondrites and lunar rocks. Geochim. Cosmochim. Acta 213, 534-552.

Grossman J. N., Alexander C. M. O’D., Wang J. and Brearley A. J. (2000) Bleached chondrules: Evidence for widespread aqueous processes on the parent asteroids of ordinary chondrites. Meteorit. Planet. Sci. 35, 467-486.

Grossman J. N. and Brearley A. J. (2005) The onset of metamorphism in ordinary and carbonaceous chondrites. Meteorit. Planet. Sci. 40, 87-122.

Grossman L. and Larimer J. W. (1974) Early chemical history of the solar system. Rev. Geophys. 12, 71-101.

Haramura H., Kushiro I. and Yanai K. (1983) Chemical compositions of Antarctic meteorites. I., National Institute of Polar Research.

Hewins R. H., Yu Y., Zanda B. and Bourot-Denise M. (1997) Do nebular fractionations, evaporative losses, or both, influence chondrule compositions? Antarct. Meteor. Res. 10, 275-298.

Hezel D. C., Harak M. and Libourel G. (2018a) What we know about elemental bulk chondrule and matrix compositions: Presenting the ChondriteDB Database. Chemie der Erde 78, 1-14.

Hezel D. C., Needham A. W., Armytage R., Georg B., Abel R. L., Kurahashi E., Coles B. J., Rehkämper M. and Russell S. S. (2010) A nebula setting as the origin for bulk chondrule Fe isotope variations in CV chondrites. Earth Planet. Sci. Lett. 296, 423433.

Hezel D. C., Wilden J. S., Becker D., Steinbach S., Wombacher F. and Harak M. (2018b) Fe isotope composition of bulk chondrules from Murchison (CM2): Constraints for parent body alteration, nebula processes and chondrule-matrix complementarity. Earth Planet. Sci. Lett. 490, 31-39.

Hin R. C., Coath C. D., Carter P. J., Nimmo F., Lai Y.-J., Pogge von Strandmann P. A. E., Willbold M., Leinhardt Z. M., Walter M. J. and Elliott T. (2017) Magnesium isotope evidence that accretional vapour loss shapes planetary compositions. Nature 549, 511-515.

Housley R. M. (1979) A model for chemical and isotopic fractionation in the lunar regolith by impact vaporization. Lunar Planet. Sci. Conf. 10, 1673-1683.

Hu Y., Chen X.-Y., Xu Y.-K. and Teng F.-Z. (2018) High-precision analysis of potassium isotopes by HR-MC-ICPMS. Chem. Geol. 493, 100-108.

Huang S. and Jacobsen S. B. (2017) Calcium isotopic compositions of chondrites. Geochim. Cosmochim. Acta 201, 364-376.

Humayun M. and Clayton R. N. (1995) Potassium isotope cosmochemistry - geneticimplications of volatile element depletion. Geochim. Cosmochim. Acta 59, 21312148.

Huss G. (2004) Implications of isotopic anomalies and presolar grains for the formation of the solar system. Antarct. Meteor. Res. 17, 132-152.

Huss G. R., Meshik A. P., Smith J. B. and Hohenberg C. M. (2003) Presolar diamond, silicon carbide, and graphite in carbonaceous chondrites: implications for thermal processing in the solar nebula. Geochim. Cosmochim. Acta 67, 4823-4848. 
Hutchison R., Alexander C. M. O. and barber D. J. (1987) The Semarkona meteorite: First recorded occurrence of smectite in an ordinary chondrite, and its implications. Geochim. Cosmochim. Acta 51, 1875-1882.

Jarosewich E. (1984) Bulk chemical analyses of Antarctic meteorites, with notes on weathering effects on FeO, Fe-metal, FeS, $\mathrm{H}_{2} \mathrm{O}$, and C. Smithson. Contrib. Earth Sci. 26, 111-114.

Jarosewich E. (1990) Chemical analyses of meteorites: A compilation of stony and iron meteorite analyses. Meteoritics 25, 323-337.

Jarosewich E. and Brian M. (1969) Chemical analyses with notes on one mesosiderite and seven chondrites. Geochim. Cosmochim. Acta 33, 411-416.

Jarosewich E. and Dodd R. T. (1985) Chemical variations among L-chondrites-IV. analyses, with petrographic notes, of 13 L-group and 3 LL-group chondrites. Meteoritics 20, 23-36.

Javoy M. (1995) The integral enstatite chondrite model of the Earth. Geophys. Res. Lett. 22, 2219-2222.

Javoy M., Kaminski E., Guyot F., Andrault D., Sanloup C., Moreira M., Labrosse S., Jambon A., Agrinier P., Davaille A. and Jaupart C. (2010) The chemical composition of the Earth: Enstatite chondrite models. Earth Planet. Sci. Lett. 293, 259-268.

Jiang Y., Chen H., Jr. B. F., Lodders K., Hsu W., Jacobsen S. B. and Wang K. (2019) Implications of $\mathrm{K}, \mathrm{Cu}$ and $\mathrm{Zn}$ isotopes for the formation of tektites. Geochim. Cosmochim. Acta 259, 170-187.

Jones R. H. (2012) Petrographic constraints on the diversity of chondrule reservoirs in the protoplanetary disk. Meteorit. Planet. Sci. 47, 1176-1190.

Kallemeyn G. W., Rubin A. E., Wang D. and Wasson J. T. (1989) Ordinary chondrites: Bulk compositions, classification, lithophile-element fractionations and composition-petrographic type relationships. Geochim. Cosmochim. Acta 53, 27472767.

Kallemeyn G. W., Rubin A. E. and Wasson J. T. (1991) The compositional classification of chondrites: V. The Karoonda (CK) group of carbonaceous chondrites. Geochim. Cosmochim. Acta 55, 881-892.

Kato C., Moynier F., Valdes M. C., Dhaliwal J. K. and Day J. M. D. (2015) Extensive volatile loss during formation and differentiation of the Moon. Nat. Commun. 6 , 7617.

Kerridge J. F., Mackay A. L. and Boynton W. V. (1979) Magnetite in CI carbonaceous meteorites: Origin by aqueous activity on a planetesimal surface. Science 205, 395397.

Krot A. N., Keil K., Scott E. R. D., Goodrich C. A. and Weisberg M. K. (2014) Classification of Meteorites and Their Genetic Relationships. Volume 1 of Treatise on Geochemistry (Second Edition) (ed. A. M. Davis). pp. 1-63.

Lewis J. A. and Jones R. H. (2016) Phosphate and feldspar mineralogy of equilibrated L chondrites: The record of metasomatism during metamorphism in ordinary chondrite parent bodies. Meteorit. Planet. Sci. 51, 1886-1913.

Lewis J. A. and Jones R. H. (2019) Primary feldspar in the Semarkona LL3.00 chondrite: Constraints on chondrule formation and secondary alteration. Meteorit. Planet. Sci. 54, 72-89. 
Leya I., Graf T., Nishiizumi K. and WielerI R. (2001) Cosmic-ray prdocution rates of helium, neon and argon isotopes in $\mathrm{H}$ chondrites based on chlorine-36/argon-36 ages. Meteorit. Planet. Sci. 36, 963-973.

Li S., Li W., Beard B. L., Raymo M. E., Wang X., Chen Y. and Chen J. (2019) K isotopes as a tracer for continental weathering and geological K cycling. Proc. Natl. Acad. Sci. U. S. A. 116, 8740-8745.

Li W., Beard B. and Li S. (2016) Precise Measurement of Stable Potassium Isotope Ratios Using A Single Focusing Collision Cell Multi-Collector ICP-MS. J. Anal. At. Spectrom., 1023-1029.

Lodders K. (2003) Solar system abundances and condensation temperatures of the elements. Astrophys. J. 591, 1220-1247.

Lodders K. and Fegley B. (2011) Chemistry of the Solar System., RSC Pub.

Lodders K. and Fegley B. (1998) The Planetary Scientist's Companion., Oxford University Press, New York.

Luck J.-M., Othman D. B., Barrat J. A. and Albarède F. (2003) Coupled 63Cu and $16 \mathrm{O}$ excesses in chondrites. Geochim. Cosmochim. Acta 67, 143-151.

Luck J.-M., Othman D. Ben, Albarède F. and Albarede F. (2005) $\mathrm{Zn}$ and $\mathrm{Cu}$ isotopic variations in chondrites and iron meteorites: Early solar nebula reservoirs and parent-body processes. Geochim. Cosmochim. Acta 69, 5351-5363.

McSween H. Y. (1979) Are carbonaceous chondrites primitive or processed? A review. Rev. Geophys. 17, 1059-1078.

Von Michaelis H., Ahrens L. H. and Willis J. P. (1968) The composition of stony meteorites II. The analytical data and an assessment of their quality. Earth Planet. Sci. Lett. 5, 387-394.

Morgan L. E., Santiago Ramos D. P., Davidheiser-Kroll B., Faithfull J., Lloyd N. S., Ellam R. and Higgins J. A. (2018) High-precision ${ }^{41} \mathrm{~K} /{ }^{39} \mathrm{~K}$ measurements by MCICP-MS indicate terrestrial variability of $\delta^{41}$ K. J. Anal. At. Spectrom. 33, 175-186.

Moynier F., Beck P., Jourdan F., Yin Q.-Z., Reimold U. and Koeberl C. (2009) Isotopic fractionation of zinc in tektites. Earth Planet. Sci. Lett. 277, 482-489.

Moynier F., Beck P., Yin Q. Z., Ferroir T., Barrat J. A., Paniello R., Telouk P. and Gillet P. (2010a) Volatilization induced by impacts recorded in $\mathrm{Zn}$ isotope composition of ureilites. Chem. Geol. 276, 374-379.

Moynier F., Blichert-Toft J., Telouk P., Luck J. M. and Albarede F. (2007) Comparative stable isotope geochemistry of $\mathrm{Ni}, \mathrm{Cu}, \mathrm{Zn}$, and $\mathrm{Fe}$ in chondrites and iron meteorites. Geochim. Cosmochim. Acta 71, 4365-4379.

Moynier F., Koeberl C., Beck P., Jourdan F. and Telouk P. (2010b) Isotopic fractionation of $\mathrm{Cu}$ in tektites. Geochim. Cosmochim. Acta 74, 799-807.

Moynier F., Paniello R. C., Gounelle M., Albarède F., Beck P., Podosek F. and Zanda B. (2011) Nature of volatile depletion and genetic relationships in enstatite chondrites and aubrites inferred from $\mathrm{Zn}$ isotopes. Geochim. Cosmochim. Acta 75, 297-307.

Mullane E., Russell S. S. and Gounelle M. (2005) Nebular and asteroidal modification of the iron isotope composition of chondritic components. Earth Planet. Sci. Lett. 239, 203-218.

Nakamura N. (1974) Determination of REE, Ba, $\mathrm{Fe}, \mathrm{Mg}, \mathrm{Na}$ and $\mathrm{K}$ in carbonaceous and ordinary chondrites. Geochim. Cosmochim. Acta 38, 757-775.

Needham A. W., Porcelli D. and Russell S. S. (2009) An Fe isotope study of ordinary 
chondrites. Geochim. Cosmochim. Acta 73, 7399-7413.

Nielsen S. G., Prytulak J., Wood B. J. and Halliday A. N. (2014) Vanadium isotopic difference between the silicate Earth and meteorites. Earth Planet. Sci. Lett. 389, $167-175$.

Palme H., Larimer J. W. and Lipschutz M. E. (1988) Moderately volatile elements. In Meteorites and the early solar system University of Arizona Press. pp. 436-461.

Palme H., Lodders K. and Jones A. (2014) Solar System Abundances of the Elements. In Planets, Asteriods, Comets and The Solar System, Volume 2 of Treatise on Geochemistry (Second Edition) (ed. A. M. Davis). pp. 15-36.

Paniello R. C., Day J. M. D. and Moynier F. (2012) Zinc isotopic evidence for the origin of the Moon. Nature 490, 376-379.

Parendo C. A., Jacobsen S. B. and Wang K. (2017) K isotopes as a tracer of seafloor hydrothermal alteration. Proc. Natl. Acad. Sci. 114, 1827-1831.

Pogge von Strandmann P. A. E., Elliott T., Marschall H. R., Coath C., Lai Y.-J., Jeffcoate A. B. and Ionov D. A. (2011) Variations of Li and $\mathrm{Mg}$ isotope ratios in bulk chondrites and mantle xenoliths. Geochim. Cosmochim. Acta 75, 5247-5268.

Poitrasson F., Halliday A. N., Lee D. C., Levasseur S. and Teutsch N. (2004) Iron isotope differences between Earth, Moon, Mars and Vesta as possible records of contrasted accretion mechanisms. Earth Planet. Sci. Lett. 223, 253-266.

Pringle E. A. and Moynier F. (2017) Rubidium isotopic composition of the Earth, meteorites, and the Moon: Evidence for the origin of volatile loss during planetary accretion. Earth Planet. Sci. Lett. 473, 62-70.

Pringle E. A., Moynier F., Beck P., Paniello R. and Hezel D. C. (2017) The origin of volatile element depletion in early solar system material: Clues from $\mathrm{Zn}$ isotopes in chondrules. Earth Planet. Sci. Lett. 468, 62-71.

Richter F. M., Dauphas N. and Teng F.-Z. (2009) Non-traditional fractionation of nontraditional isotopes: Evaporation, chemical diffusion and Soret diffusion. Chem. Geol. 258, 92-103.

Richter F. M., Mendybaev R. A., Christensen J. N., Ebel D. and Gaffney A. (2011) Laboratory experiments bearing on the origin and evolution of olivine-rich chondrules. Meteorit. Planet. Sci. 46, 1152-1178.

Ringwood A. E. (1966) Chemical evolution of the terrestrial planets. Geochim. Cosmochim. Acta 30, 41-104.

Rubin A. E. (2000) Petrologic, geochemical and experimental constraints on models of chondrule formation. Earth-Science Rev. 50, 3-27.

Rubin A. E. (2010) Physical properties of chondrules in different chondrite groups: Implications for multiple melting events in dusty environments. Geochim. Cosmochim. Acta 74, 4807-4828.

Rubin A. E. (1989) Size-frequency distributions of chondrules in CO3 chondrites. Meteoritics 24, 179-189.

Rubin A. E., Zolensky M. E. and Bodnar R. J. (2002) The halite-bearing Zag and Monahans (1998) meteorite breccias: Shock metamorphism, thermal metamorphism and aqueous alteration on the H-chondrite parent body. Meteorit. Planet. Sci. 37, $125-141$.

Rudnick R. L. and Gao S. (2014) Composition of the Continental Crust. Volume 4 of Treatise on Geochemistry (Second Edition) (ed. R. L. Rudnick). pp. 1-51. 
Satterwhite C. (2013) Macroscopic Description of LAR 12002. Antarct. Meteor. Newsl. 36, 15.

Schiller M., Handler M. R. and Baker J. A. (2010) High-precision Mg isotopic systematics of bulk chondrites. Earth Planet. Sci. Lett. 297, 165-173.

Shu F. H., Shang H., Glassgold A. E. and Lee T. (1997) X-rays and fluctuating x-winds from protostars. Science 277, 1475-1479.

Simon J. I. and DePaolo D. J. (2010) Stable calcium isotopic composition of meteorites and rocky planets. Earth Planet. Sci. Lett. 289, 457-466.

Sossi P. A. and Fegley B. (2018) Thermodynamics of Element Volatility and its Application to Planetary Processes. Rev. Mineral. Geochemistry 84, 393-459.

Teng F.-Z., Li W.-Y., Ke S., Marty B., Dauphas N., Huang S., Wu F.-Y. and Pourmand A. (2010) Magnesium isotopic composition of the Earth and chondrites. Geochim. Cosmochim. Acta 74, 4150-4166.

Tian Z., Chen H., Fegley B., Lodders K., Barrat J.-A., Day J. M. D. and Wang K. (2019) Potassium isotopic compositions of howardite-eucrite-diogenite meteorites. Geochim. Cosmochim. Acta 266, 611-632.

Valdes M. C., Moreira M., Foriel J. and Moynier F. (2014) The nature of Earth's building blocks as revealed by calcium isotopes. Earth Planet. Sci. Lett. 394, 135-145.

Velbel M. A., Long D. T. and Gooding J. L. (1991) Terrestrial weathering of Antarctic stone meteorites: Formation of Mg-carbonates on ordinary chondrites. Geochim. Cosmochim. Acta 55, 67-76.

Wai C. M. and Wasson J. T. (1977) Nebular condensation of moderately volatile elements and their abundances in ordinary chondrites. Earth Planet. Sci. Lett. 36, 113.

Wang K. and Jacobsen S. B. (2016a) An estimate of the Bulk Silicate Earth potassium isotopic composition based on MC-ICPMS measurements of basalts. Geochim. Cosmochim. Acta 178, 223-232.

Wang K. and Jacobsen S. B. (2016b) Potassium isotopic evidence for a high-energy giant impact origin of the Moon. Nature 538, 487-490.

Wang K., Moynier F., Barrat J.-A., Zanda B., Paniello R. C. and Savage P. S. (2013) Homogeneous distribution of $\mathrm{Fe}$ isotopes in the early solar nebula. Meteorit. Planet. Sci. 48, 354-364.

Warren P. H. (2011a) Stable-isotopic anomalies and the accretionary assemblage of the Earth and Mars: A subordinate role for carbonaceous chondrites. Earth Planet. Sci. Lett. 311, 93-100.

Warren P. H. (2011b) Stable isotopes and the noncarbonaceous derivation of ureilites, in common with nearly all differentiated planetary materials. Geochim. Cosmochim. Acta 75, 6912-6926.

Wasson J. T. and Chou C.-L. (1974) Fractionation of Moderately Volatile Elements in Ordinary Chondrites. Meteoritics 9, 69-84.

Wiik H. B. (1969) On the regular discontinuities in the composition of meteorites. Comment. Physico-Mathematicae 34, 135-145.

Xue Y., Li C., Qi Y., Zhang C., Miao B. and Huang F. (2018) The vanadium isotopic composition of L ordinary chondrites. Acta Geochim. 37, 501-508.

Yanai K., Kojima H. and Haramura H. (1995) Catalog of the Antarctic Meteorites collected from December 1969 to December 1994, with special reference to those 
represented in the collections of the National Institute of Polar Research., National Institut of Polar Research, Tokyo.

Yin Q. (2005) From dust to planets: The tale told by moderately volatile elements. Chondrites protoplanetary Disk 341, 632-644.

Young E. D. (2000) Assessing the implications of K isotope cosmochemistry for evaporation in the preplanetary solar nebula. Earth Planet. Sci. Lett. 183, 321-333.

Young E. D., Shahar A., Nimmo F., Schlichting H. E., Schauble E. A., Tang H. and Labidi J. (2019) Near-equilibrium isotope fractionation during planetesimal evaporation. Icarus 323, 1-15.

Yu Y., Hewins R. H., Alexander C. M. O'D. and Wang J. (2003) Experimental study of evaporation and isotopic mass fractionation of potassium in silicate melts. Geochim. Cosmochim. Acta 67, 773-786.

Zhao C., Lodders K., Bloom H., Chen H., Tian Z., Koefoed P., Pető M. K., and Wang K. (2019) Potassium isotopic compositions of enstatite meteorites. Meteorit. Planet. Sci. in press, maps. 13358.

Zipfel J., Scherer P., Spettel B., Dreibus G. and Schultz L. (2000) Petrology and chemistry of the new shergottite Dar al Gani 476. Meteorit. Planet. Sci. 35, 95-106.

Zolensky M. E., Bodnar R. J., Gibson E. K., Nyquist L. E., Reese Y., Shih C.-Y. and Wiesmann H. (1999) Asteroidal water within fluid inclusion-bearing halite in an H5 chondrite, Monahans (1998). Science 285, 1377-1379. 
Table 1 . The $\mathbf{K}$ concentration and isotopic compositions of carbonaceous chondrites in this study and from literature.

\begin{tabular}{|c|c|c|c|c|c|c|c|c|c|c|c|c|}
\hline Sample & Type & $\begin{array}{l}\text { Fall } \\
\text { /Find }\end{array}$ & $\begin{array}{l}\text { Mass } \\
{[\mathrm{mg}]}\end{array}$ & $\begin{array}{l}\text { K } \\
\text { [ppm] } \\
\text { this study }\end{array}$ & $\begin{array}{l}\mathbf{K} \\
\text { [ppm] } \\
\text { literature }\end{array}$ & $\begin{array}{l}\delta^{41} K_{\text {NIST }} \\
{[\% \text { ] }}\end{array}$ & $95 \%$ c.i. ${ }^{a}$ & $\overline{\mathbf{n}^{b}}$ & $\begin{array}{l}\text { Shock } \\
\text { Level }^{c}\end{array}$ & $\begin{array}{l}\text { Weathering } \\
\text { Grade }^{c}\end{array}$ & Source $^{d}$ & Literature \\
\hline \multicolumn{13}{|l|}{$\overline{C I}$} \\
\hline Orgueil & CI1 & Fall & & & & -0.53 & 0.11 & 11 & & & & (Wang and Jacobsen, 2016b) \\
\hline \multicolumn{13}{|l|}{$C M$} \\
\hline ALH 83100 & $\mathrm{CM} 1 / 2$ & Find & 107.1 & 234 & 415 & -0.18 & 0.04 & 10 & & $\mathrm{Be}$ & ANSMET & (Jarosewich, 1990) \\
\hline ALH $85013 \# 1$ & $\mathrm{CM} 2$ & Find & 157.0 & & & -0.39 & 0.03 & 10 & & $\mathrm{~A}$ & ANSMET & \\
\hline ALH $85013 \# 2$ & $\mathrm{CM} 2$ & Find & 101.1 & 159 & & -0.38 & 0.03 & 12 & & $\mathrm{~A}$ & ANSMET & \\
\hline EET 96029 & $\mathrm{CM} 2$ & Find & 103.6 & 192 & & -0.09 & 0.03 & 11 & & $\mathrm{~A} / \mathrm{B}$ & ANMSET & \\
\hline \multirow[t]{2}{*}{ LON 94101} & $\mathrm{CM} 2$ & Find & 101.4 & 290 & & -0.22 & 0.03 & 10 & & $\mathrm{Be}$ & ANSMET & \\
\hline & & & & & $\mathrm{CM}$ average $=$ & -0.25 & $0.26^{\mathrm{f}}$ & & & & & \\
\hline \multicolumn{13}{|l|}{$\mathrm{CO}$} \\
\hline MIL 090010 & $\mathrm{CO} 3$ & Find & 113.1 & 218 & & -0.17 & 0.02 & 11 & & $\mathrm{~A} / \mathrm{B}$ & ANSMET & \\
\hline MIL 11213 \#1 & $\mathrm{CO} 3$ & Find & 123.0 & & & 0.36 & 0.05 & 13 & & A & ANSMET & \\
\hline MIL 11213 \#2 & $\mathrm{CO} 3$ & Find & 108.5 & 82 & & 0.02 & 0.03 & 12 & & A & ANSMET & \\
\hline ALH 83108 & $\mathrm{CO} 3.5$ & Find & & & & -0.35 & 0.07 & 19 & S1 & $\mathrm{A}$ & ANSMET & \\
\hline \multirow[t]{2}{*}{ ALHA77003 } & $\mathrm{CO} 3.6$ & Find & 109.0 & 253 & 500 & -0.30 & 0.03 & 10 & S1 & $\mathrm{Ae}$ & ANSMET & (Jarosewich, 1984) \\
\hline & & & & & CO average $=$ & -0.09 & $0.58^{\mathrm{f}}$ & & & & & \\
\hline \multicolumn{13}{|l|}{$C V$} \\
\hline Allende \#1 & CV3 & Fall & & & & -0.34 & 0.02 & 32 & S1 & & & \\
\hline
\end{tabular}




\begin{tabular}{|c|c|c|c|c|c|c|c|c|c|c|c|c|}
\hline Allende \#2 & $\mathrm{CV} 3$ & Fall & & & & -0.53 & 0.03 & 31 & S1 & & & \\
\hline LAR $12002 \# 1$ & CV3 & Find & 114.5 & 539 & & -1.45 & 0.04 & 10 & & $\mathrm{~A} / \mathrm{B}$ & ANSMET & \\
\hline LAR $12002 \# 2$ & CV3 & Find & & & & -1.54 & 0.03 & 11 & & $\mathrm{~A} / \mathrm{B}$ & ANSMET & \\
\hline \multirow[t]{2}{*}{ GRA 06101} & $\mathrm{CV} 3$ & Find & 106.4 & 167 & & -0.30 & 0.02 & 10 & & B & ANSMET & \\
\hline & & & & & $\mathrm{CV}$ average $^{\mathrm{g}}=$ & -0.39 & $0.25^{\mathrm{f}}$ & & & & & \\
\hline \multicolumn{13}{|l|}{ CR } \\
\hline GRA $06100 \# 1$ & $\mathrm{CR} 2$ & Find & 111.0 & & & 0.16 & 0.03 & 16 & & B & ANSMET & \\
\hline \multirow[t]{2}{*}{ GRA $06100 \# 2$} & $\mathrm{CR} 2$ & Find & 113.8 & 216 & & 0.70 & 0.02 & 9 & & B & ANSMET & \\
\hline & & & & & $\mathrm{CR}$ average $=$ & 0.43 & $0.77^{\mathrm{f}}$ & & & & & \\
\hline \multicolumn{13}{|l|}{ CK } \\
\hline ALH $85002 \# 1$ & CK4 & Find & 108.0 & & 247 & -0.07 & 0.02 & 16 & $\mathrm{~S} 2$ & A & ANSMET & (Kallemeyn et al., 1991) \\
\hline ALH $85002 \# 2$ & CK4 & Find & 109.7 & 407 & 247 & -0.06 & 0.04 & 12 & $\mathrm{~S} 2$ & A & ANSMET & (Kallemeyn et al., 1991) \\
\hline ALH $85002 \# 3$ & CK4 & Find & & & 247 & -0.11 & 0.05 & 9 & $\mathrm{~S} 2$ & A & ANSMET & (Kallemeyn et al., 1991) \\
\hline EET 92002 & CK5 & Find & 109.5 & 185 & & -0.15 & 0.04 & 9 & & $\mathrm{~A} / \mathrm{Be}$ & ANSMET & \\
\hline \multirow[t]{2}{*}{ RBT 03522} & CK5 & Find & 122.0 & 198 & & -0.36 & 0.03 & 11 & & B & ANSMET & \\
\hline & & & & & $\mathrm{CK}$ average $=$ & -0.15 & $0.25^{\mathrm{f}}$ & & & & & \\
\hline \multicolumn{13}{|l|}{$\boldsymbol{C H}$} \\
\hline \multirow[t]{2}{*}{ PCA 91467} & $\mathrm{CH} 3$ & Find & 104.3 & 132 & & -0.64 & 0.03 & 10 & $\mathrm{~S} 1$ & $\mathrm{~B} / \mathrm{C}$ & ANSMET & \\
\hline & & & & & CC average $^{\mathrm{h}}=$ & -0.29 & $0.34^{\mathrm{f}}$ & & & & & \\
\hline Geostandard & & & & & & & & & & & & \\
\hline
\end{tabular}


${ }^{a}$ The brecciation conditions are from literatures: Orgueil (Endress and Bischoff, 1993); ALH 83100 (Endress and Bischoff, 1993);

${ }^{\mathrm{b}} 95 \%$ confidence interval (c.i.): $\mathrm{z} \times[\sigma / \sqrt{ }(\mathrm{n}-1)]$, where $\mathrm{z}$ is the student's $\mathrm{t}$ number, $\sigma=$ standard deviation, and $\mathrm{n}=$ number of measurements

$5 \quad{ }^{\mathrm{c}}$ Number of measurements

d The shock level and weathering grade are from MetBase and references therein. Weathering grade A, B or C represents "minor", "moderate" or "severe" rustiness, respectively. Letter "e" represents evaporite minerals visible.

${ }^{\mathrm{e}}$ ANSMET $=$ The Antarctic Search for Meteorites program. USGS $=$ The United States Geological Survey.

${ }^{\mathrm{f}} 2$ standard deviation $(2 \mathrm{SD})$

g except of LAR 12002

${ }^{\mathrm{h}}$ except of MIL 11213, LAR 12002, GRA 06100. 
Table 2. The $K$ concentration and isotopic compositions of ordinary chondrites in this study and from literature.

\begin{tabular}{|c|c|c|c|c|c|c|c|c|c|c|c|c|c|}
\hline Sample & Type & $\begin{array}{l}\text { Fall } \\
\text { /Find }\end{array}$ & $\begin{array}{c}\text { Breccia } \\
\text { tion }^{a}\end{array}$ & $\begin{array}{l}\text { Mass } \\
{[\mathrm{mg}]}\end{array}$ & $\begin{array}{c}\text { K } \\
\text { [ppm] } \\
\text { this } \\
\text { study } \\
\end{array}$ & $\begin{array}{l}\text { K } \\
\text { [ppm] } \\
\text { literature }\end{array}$ & $\begin{array}{r}\delta^{41} K_{\text {NIST }} \\
{[\% \text { o] }}\end{array}$ & $\begin{array}{l}95 \\
\% \\
\text { c.i. }{ }^{b}\end{array}$ & $\overline{\mathbf{n}^{c}}$ & $\begin{array}{l}\text { Shock } \\
\text { Level }^{d}\end{array}$ & $\begin{array}{l}\text { Weathering } \\
\text { Grade }^{d}\end{array}$ & Source $^{e}$ & Literature \\
\hline \multicolumn{14}{|l|}{$\boldsymbol{H}$} \\
\hline MET 00526 & H3.05 & Find & & & & & -0.88 & 0.05 & 8 & $\mathrm{~S} 2$ & $\mathrm{~B} / \mathrm{C}$ & ANMSET & \\
\hline $\begin{array}{l}\text { ALHA } \\
77299\end{array}$ & H3.7 & Find & & & & $640-1330$ & -0.34 & 0.05 & 14 & & A & ANSMET & $\begin{array}{l}\text { (Fulton and } \\
\text { Rhodes, 1984; } \\
\text { Brearley et al., } \\
\text { 1989) }\end{array}$ \\
\hline Ochansk \#1 & $\mathrm{H} 4$ & Fall & & & & $660-858$ & -1.08 & 0.05 & 13 & & & $\begin{array}{l}\text { The Field } \\
\text { Museum } \\
\text { (ME 1443\#15) }\end{array}$ & $\begin{array}{l}\text { (Easton and } \\
\text { Elliott, 1977; } \\
\text { Leya et al., } \\
2001 \text { ) }\end{array}$ \\
\hline Ochansk \#2 & $\mathrm{H} 4$ & Fall & & 121.5 & 784 & $660-858$ & -1.00 & 0.04 & 10 & & & $\begin{array}{l}\text { The Field } \\
\text { Museum } \\
\text { (ME 1443\#15) }\end{array}$ & $\begin{array}{l}\text { (Easton and } \\
\text { Elliott, 1977; } \\
\text { Leya et al., } \\
2001 \text { ) }\end{array}$ \\
\hline Ochansk \#3 & $\mathrm{H} 4$ & Fall & & & & $660-858$ & -1.01 & 0.05 & 11 & & & $\begin{array}{l}\text { The Field } \\
\text { Museum } \\
\text { (ME 1443\#15) }\end{array}$ & $\begin{array}{l}\text { (Easton and } \\
\text { Elliott, 1977; } \\
\text { Leya et al., } \\
\text { 2001) }\end{array}$ \\
\hline $\begin{array}{l}\text { RKPA } \\
78004\end{array}$ & H4 & Find & & & & & 0.00 & 0.03 & 14 & $\mathrm{~S} 4$ & A & ANSMET & \\
\hline Weston \#1 & $\mathrm{H} 4$ & Fall & Yes & 107.6 & 316 & 830 & -0.82 & 0.04 & 12 & & & $\begin{array}{l}\text { The Field } \\
\text { Museum } \\
\text { (ME 1835\#6) }\end{array}$ & $\begin{array}{l}\text { (Fulton and } \\
\text { Rhodes, 1984) }\end{array}$ \\
\hline Weston \#2 & H4 & Fall & Yes & & & 830 & -0.54 & 0.04 & 13 & & & $\begin{array}{l}\text { The Field } \\
\text { Museum } \\
\text { (ME 1835\#6) }\end{array}$ & \\
\hline ALHA77279 & H5 & Find & & & & & -0.80 & 0.06 & 11 & & A & ANSMET & \\
\hline $\begin{array}{l}\text { ALH } 84069 \\
\# 1\end{array}$ & H5 & Find & & & & & -0.76 & 0.04 & 8 & & A & ANSMET & \\
\hline $\begin{array}{l}\text { ALH } 84069 \\
\# 2\end{array}$ & H5 & Find & & 108.0 & 480 & & -0.80 & 0.05 & 10 & & A & ANSMET & \\
\hline Jilin \#1 & H5 & Fall & No & 108.5 & 632 & $660-792$ & -1.18 & 0.02 & 14 & S3 & & The Field & (Kallemeyn et \\
\hline
\end{tabular}




\begin{tabular}{|c|c|c|c|c|c|c|c|c|c|c|c|c|c|}
\hline & & & & & & & & & & & & $\begin{array}{l}\text { Museum } \\
(\mathrm{ME} 3.53 \# 2)\end{array}$ & $\begin{array}{l}\text { al., 1989; } \\
\text { Yanai et al., } \\
1995)\end{array}$ \\
\hline Jilin \#2 & H5 & Fall & No & & & $660-793$ & -1.28 & 0.05 & 12 & $\mathrm{~S} 3$ & & $\begin{array}{l}\text { The Field } \\
\text { Museum } \\
\text { (ME 3.53\#2) }\end{array}$ & $\begin{array}{l}\text { (Kallemeyn et } \\
\text { al., 1989; } \\
\text { Yanai et al., } \\
\text { 1995) }\end{array}$ \\
\hline $\begin{array}{l}\text { PRE } 95400 \\
\# 1\end{array}$ & H5 & Find & & & & & 0.07 & 0.03 & 10 & & A & ANSMET & \\
\hline $\begin{array}{l}\text { PRE } 95400 \\
\# 2\end{array}$ & H5 & Find & & 106.9 & 613 & & 0.04 & 0.05 & 10 & & A & ANSMET & \\
\hline Guareña \#1 & H6 & Fall & & & & $750-974$ & -0.68 & 0.09 & 9 & $\mathrm{~S} 1$ & & & $\begin{array}{l}\text { (Jarosewich } \\
\text { and Brian, } \\
1969 ; \\
\text { Nakamura, } \\
\text { 1974) }\end{array}$ \\
\hline Guareña \#2 & H6 & Fall & & & & $750-975$ & -0.67 & 0.07 & 8 & $\mathrm{~S} 1$ & & & $\begin{array}{l}\text { (Jarosewich } \\
\text { and Brian, } \\
1969 ; \\
\text { Nakamura, } \\
\text { 1974) }\end{array}$ \\
\hline \multirow[t]{2}{*}{ QUE 90203} & H6 & Find & & & & & -0.95 & 0.06 & 11 & & A & ANSMET & \\
\hline & & & & & & $\mathrm{H}$ average $=$ & -0.70 & $0.81^{\mathrm{f}}$ & & & & & \\
\hline \multicolumn{14}{|l|}{$L$} \\
\hline QUE 97008 & L3.05 & Find & & & & & -0.85 & 0.02 & 8 & $\mathrm{~S} 2$ & A & ANSMET & \\
\hline $\begin{array}{l}\text { GRO } 06054 \\
\# 1\end{array}$ & L3.6 & Find & & & & & -0.87 & 0.03 & 8 & & & ANSMET & \\
\hline $\begin{array}{l}\text { GRO } 06054 \\
\# 2\end{array}$ & L3.6 & Find & & 107.3 & 492 & & -1.01 & 0.04 & 7 & & & ANSMET & \\
\hline $\begin{array}{l}\text { GRO } 06054 \\
\# 3\end{array}$ & L3.6 & Find & & & & & -0.89 & 0.05 & 10 & & & ANSMET & \\
\hline ALH 85033 & L4 & Find & & & & & -0.92 & 0.08 & 9 & S6 & $\mathrm{A} / \mathrm{B}$ & ANSMET & \\
\hline Bjurböle & L/LL4 & Fall & Yes & 104.6 & 530 & $820-1000$ & -0.83 & 0.05 & 12 & $\mathrm{~S} 1$ & & $\begin{array}{l}\text { The Field } \\
\text { Museum } \\
\text { (ME 1428\#14) }\end{array}$ & $\begin{array}{l}\text { (Von } \\
\text { Michaelis et } \\
\text { al., 1968; } \\
\text { Easton and } \\
\text { Elliott, 1977) }\end{array}$ \\
\hline GRO 95530 & L5 & Find & & & & & -0.72 & 0.06 & 12 & & A & ANSMET & \\
\hline Homestead & L5 & Fall & Yes & 102.2 & 796 & 1080 & -1.14 & 0.03 & 12 & S4 & & The Field & $\begin{array}{l}\text { (Jarosewich } \\
\text { and Dodd, }\end{array}$ \\
\hline
\end{tabular}




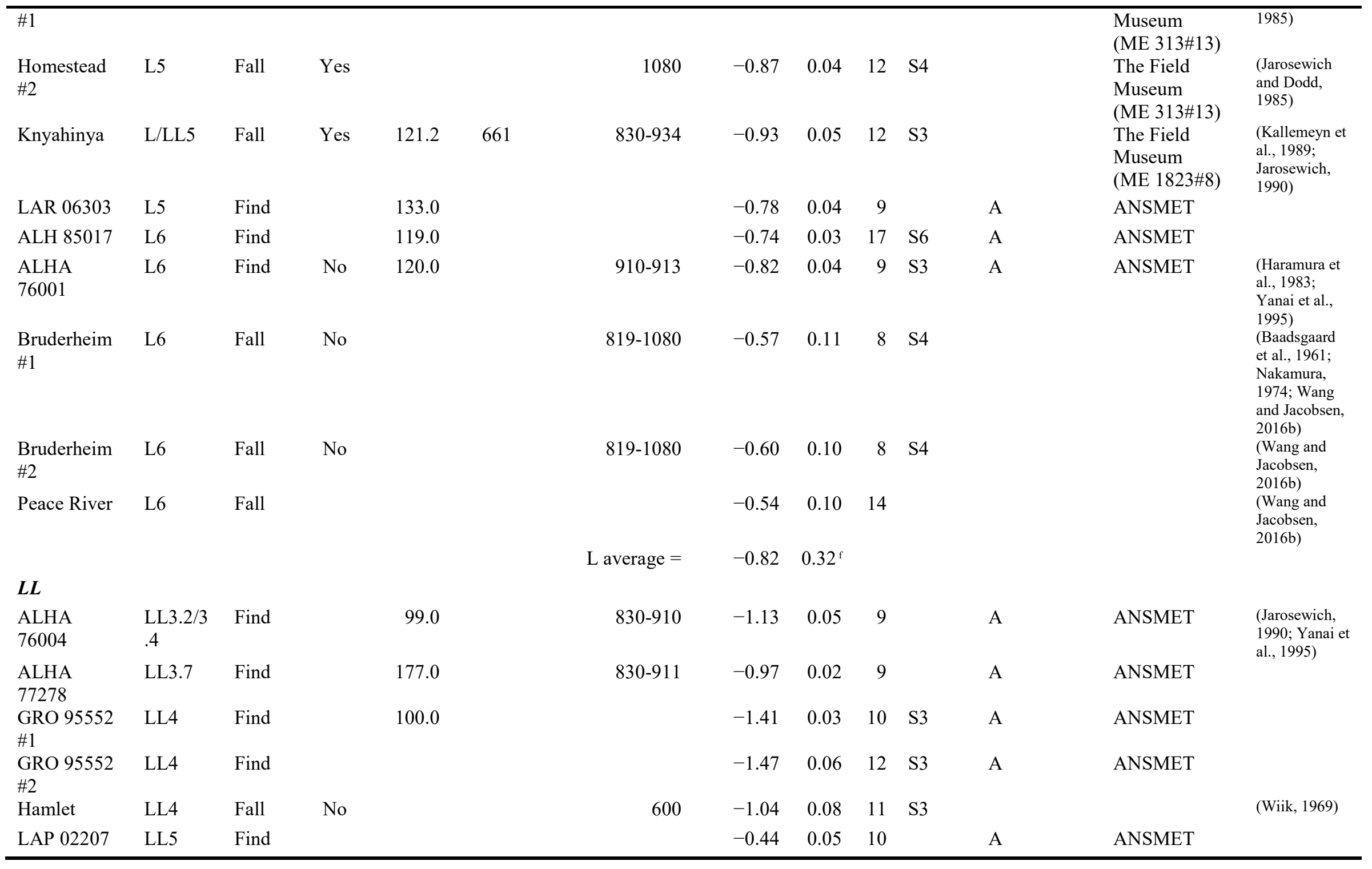




\begin{tabular}{|c|c|c|c|c|c|c|c|c|c|c|}
\hline $\begin{array}{l}\text { RBT } 04127 \\
\# 1\end{array}$ & LL5 & Find & 177.0 & & & -0.84 & 0.02 & 8 & & ANSMET \\
\hline $\begin{array}{l}\text { RBT } 04127 \\
\# 2\end{array}$ & LL5 & Find & 101.3 & 532 & & -0.67 & 0.04 & 10 & & ANSMET \\
\hline PRA 04405 & LL6 & Find & & & & -0.72 & 0.05 & 11 & A & ANSMET \\
\hline $\begin{array}{l}\text { PRA } 04422 \\
\# 1\end{array}$ & LL6 & Find & 98.0 & & & -0.86 & 0.03 & 16 & A & ANSMET \\
\hline \multirow[t]{3}{*}{$\begin{array}{l}\text { PRA } 04422 \\
\text { \#2 }\end{array}$} & LL6 & Find & 111.5 & 524 & & -0.94 & 0.03 & 7 & A & ANSMET \\
\hline & & & & & LL average $=$ & -0.95 & $0.61^{\mathrm{f}}$ & & & \\
\hline & & & & & OC average $=$ & -0.81 & $0.64^{\mathrm{f}}$ & & & \\
\hline \multicolumn{11}{|l|}{ Geostandard } \\
\hline BHVO-2 & & & & & & -0.49 & 0.03 & 11 & & USGS \\
\hline
\end{tabular}

${ }^{a}$ The brecciation conditions are determined by Bischoff et al. (2018).

$20 \quad \mathrm{~b} 95 \%$ confidence interval (c.i.): $\mathrm{z} \times[\sigma / \sqrt{ }(\mathrm{n}-1)]$, where $\mathrm{z}$ is the student's $\mathrm{t}$ number, $\sigma=$ standard deviation, and $\mathrm{n}=$ number of measurements

${ }^{c}$ Number of measurements

d The shock level and weathering grade are from MetBase and references therein. Weathering grade A, B or C represents "minor", "moderate" or "severe" rustiness, respectively. Letter "e" represents evaporite minerals visible.

e ANSMET = The Antarctic Search for Meteorites program. USGS = The United States Geological Survey.
25 f 2 standard deviation (2SD). 


\section{Figure Captions:}

30 Figure 1. The ratios of $\mathrm{K} / \mathrm{Si}, \mathrm{Cu} / \mathrm{Si}, \mathrm{Rb} / \mathrm{Si}$ and $\mathrm{Zn} / \mathrm{Si}$ in different chemical groups of chondrites and bulk planetary bodies (Earth, Mars, Moon, and Vesta) normalized to those ratios in CI chondrites. The ratios of the solar photosphere are also shown. All data are from the compilation by Lodders and Fegley (1998; 2011). The volatilities of the elements are expressed as their $50 \%$ nebular condensation temperatures (Lodders, 2003).

Figure 2. The bulk K isotopic compositions of carbonaceous chondrites (A) and ordinary chondrites (B) in this study and literature (Wang and Jacobsen, 2016b).

Figure 3. The bulk $\mathrm{K}$ isotopic compositions of carbonaceous chondrites (A) and ordinary chondrites (B) vs. the weathering grades. The dashed line represents the BSE value $(-0.5$ $\%$ ).

Figure 4. K isotopic compositions versus $\mathrm{K} / \mathrm{U}$ ( $\mathrm{ppm} / \mathrm{ppm}$; normalized to $\mathrm{CI}$ ) and $\mathrm{K} / \mathrm{Al}$ ( $\mathrm{ppm} / \mathrm{ppm}$; normalized to $\mathrm{CI}$ ) ratios and $\mathrm{K}$ abundance (ppm; normalized to $\mathrm{CI}$ ) of carbonaceous and ordinary chondrites samples from this study and literature (Jarosewich, 1984; Fulton and Rhodes, 1984; Jarosewich and Dodd, 1985; Kallemeyn et al., 1989; Kallemeyn et al., 1991; Yanai et al., 1995; Wang and Jacobsen, 2016b). The analytical errors are smaller than the sizes of the symbols if not shown. The dash line represents the BSE value $(-0.5 \%)$.

Figure 5. Range of $\mathrm{K}$ isotopic compositions of carbonaceous chondrites (A), $\mathrm{H}$ chondrites (B), L chondrites (C) and LL chondrites (D) vs. petrological types. The middle line represents the median of the data. The box extends from the $25^{\text {th }}$ to $75^{\text {th }}$ percentiles of the data. The bars mark the maximum and minimum values of each petrological type. The triangles indicate outlier. The dashed line represents the BSE value $(-0.5 \%)$. N

55 represents the number of samples (including the different fragments/chips of the same meteorites in order to show the sample heterogeneity).

Figure 6. Mixing model of K concentrations (A) and $K$ isotopic compositions (B) of carbonaceous chondrites based on Alexander (2019). The K concentrations normalized to $60 \mathrm{Si}$ and CI are from compilation by Alexander (2019). The K isotope data are from this study and literature (Wang and Jacobsen, 2016b). The percentages indicate the percentages of $\mathrm{K}$ loss during chondrule formation based on our Rayleigh modeling (see Discussion Section 4.2). 
65 Figure 7. $\mathrm{K}$ isotope compositions versus $\mathrm{Zn}$ isotope (A), $\mathrm{Cu}$ isotope (B), and $\mathrm{Rb}$ isotope (C) compositions of carbonaceous and ordinary chondrites from this study and literatures (Luck et al., 2003; Luck et al., 2005; Moynier et al., 2007; Barrat et al., 2012; Wang and Jacobsen, 2016b; Pringle et al., 2017; Pringle and Moynier, 2017). The error bars for Zn, $\mathrm{Cu}$, and $\mathrm{Rb}$ isotopes are the reported analytical uncertainties (2SD) from the literatures.

Figure 8. Histograms and relative Probability Density Function (PDF) of K isotopic compositions of carbonaceous chondrites, ordinary chondrites, and enstatite chondrites from this study and literature (Wang and Jacobsen, 2016b; Zhao et al., 2019). The dash line represents the BSE value $(-0.5 \%$ ). $\mathrm{N}$ represents the number of meteorites (not including the different fragments/chips of the same meteorites). 

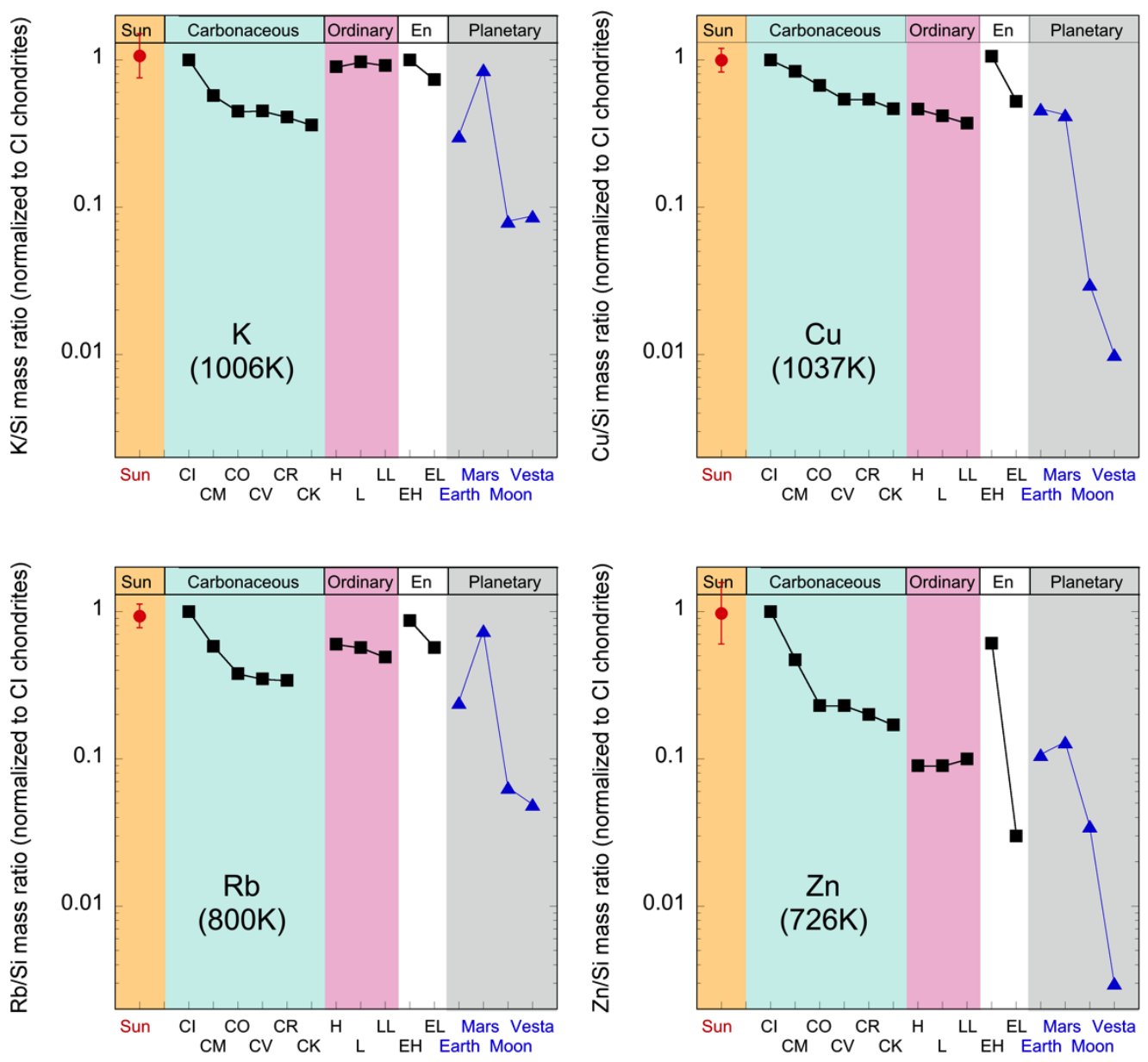

Figure 1 


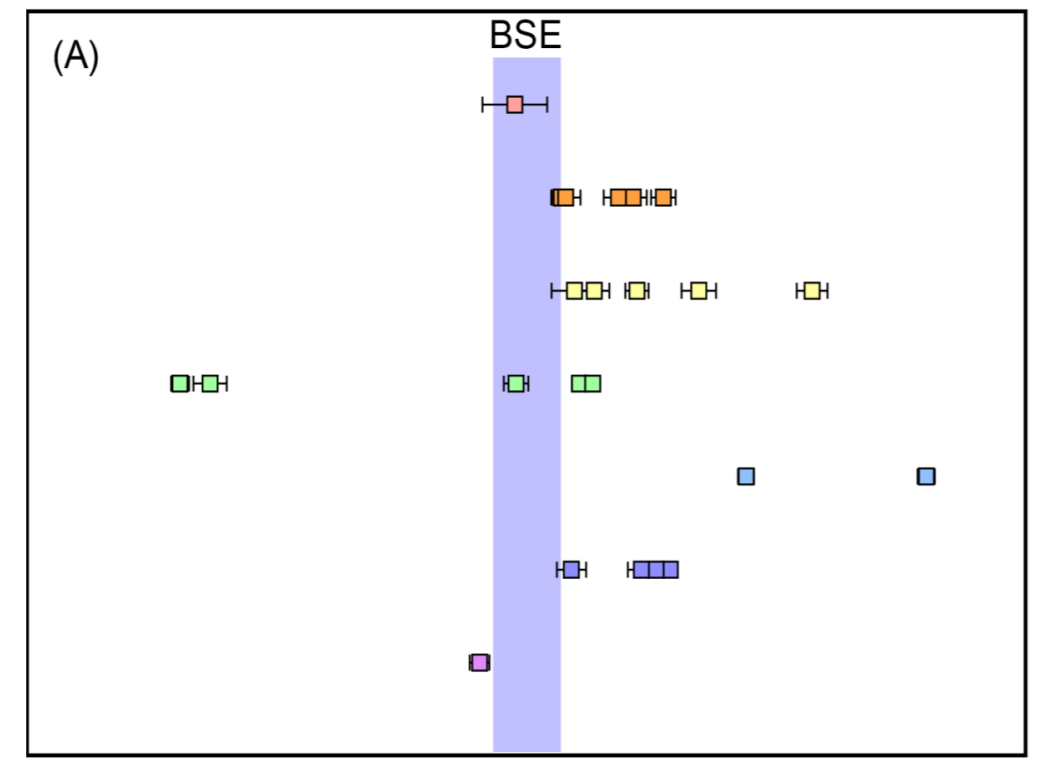

$\square \mathrm{Cl}$

- $\mathrm{CM}$

- CO

- CV

口 $\mathrm{CR}$

- CK

$\square \mathrm{CH}$

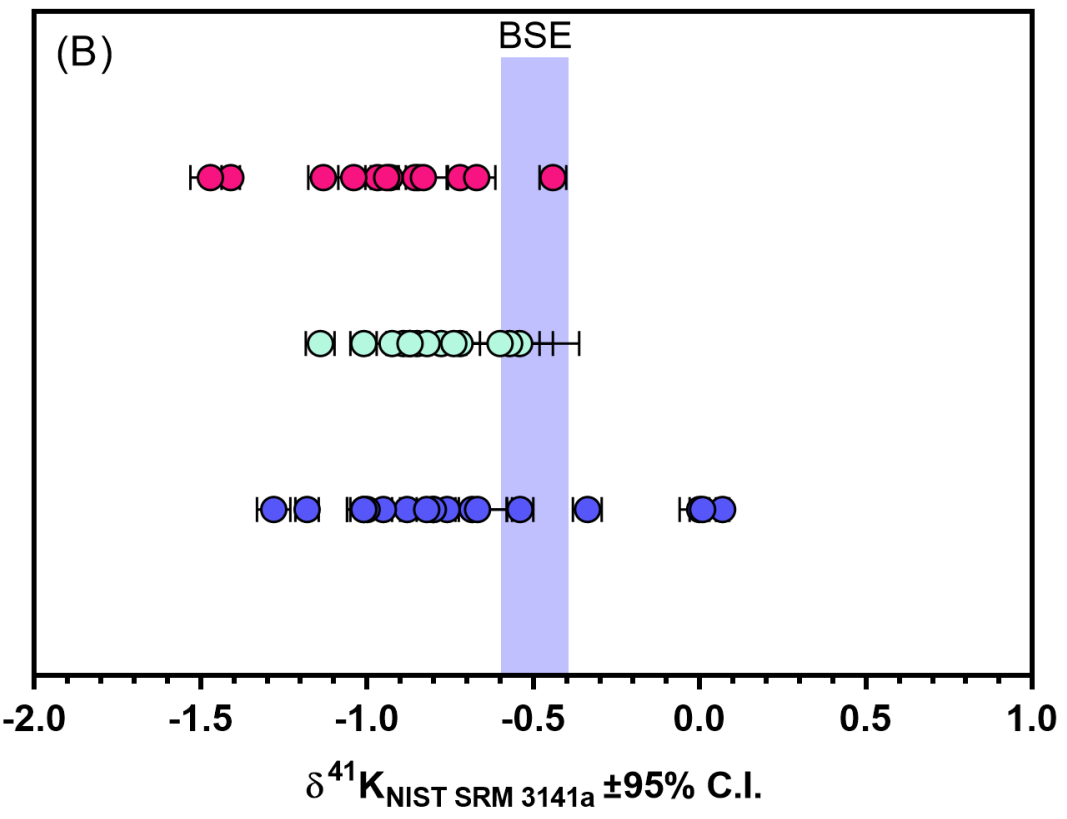

○ LL

O L

○ $\mathrm{H}$ 


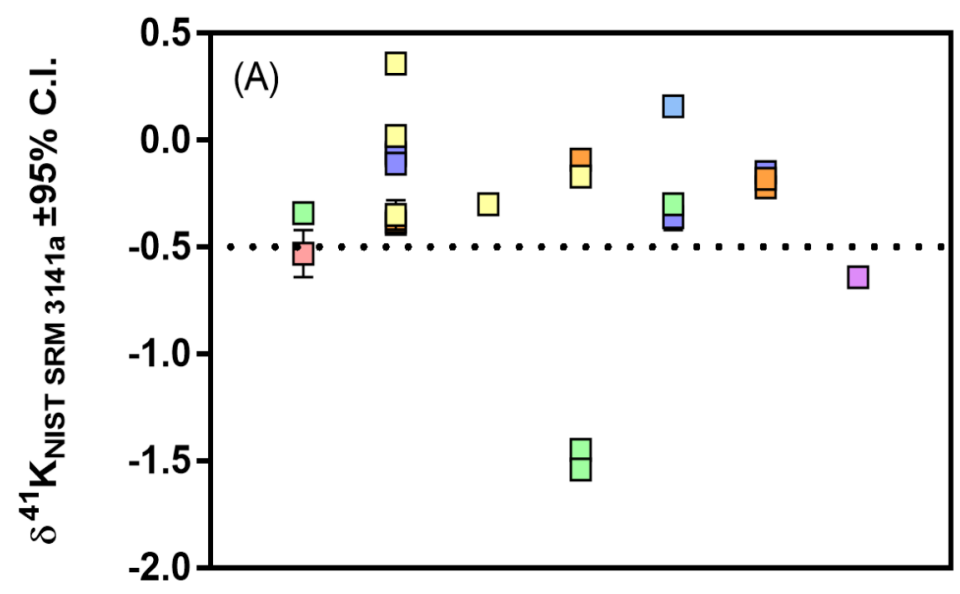

$\begin{array}{ll}\square & \mathrm{Cl} \\ \square & \mathrm{CM} \\ \square & \mathrm{CO} \\ \square & \mathrm{CV} \\ \square & \mathrm{CK} \\ \square & \mathrm{CR} \\ \square & \mathrm{CH}\end{array}$

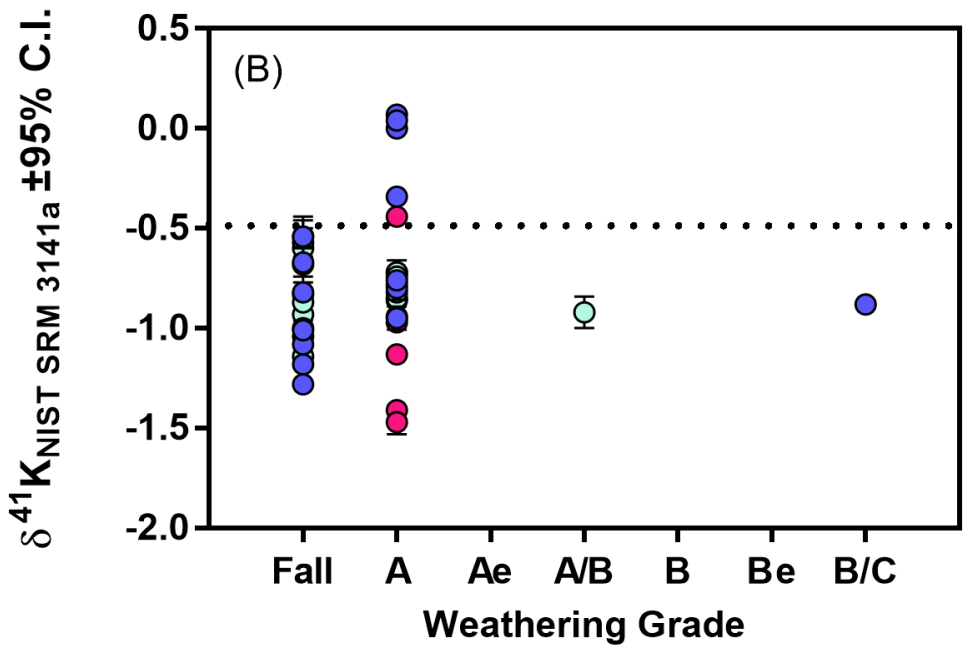

- $\mathrm{H}$

○ L

- LL

Figure 3 

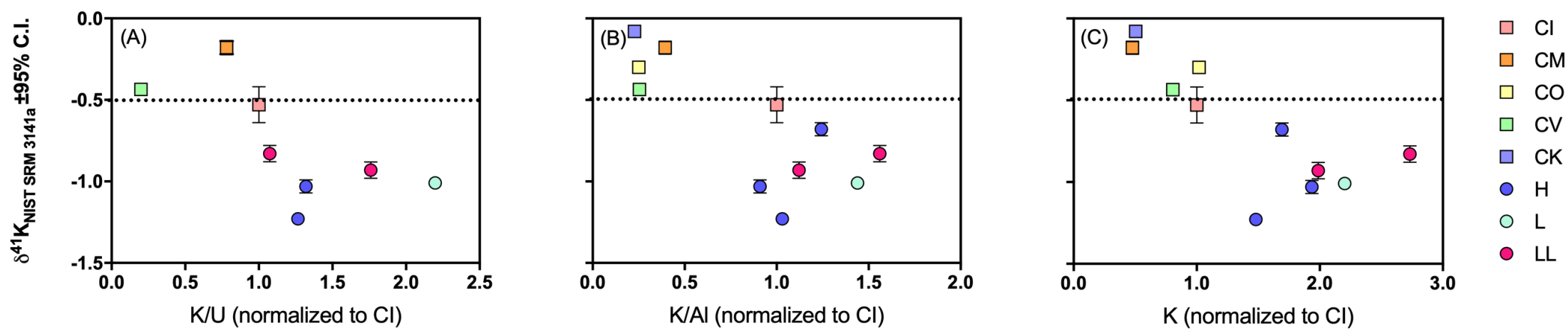

Figure 4 

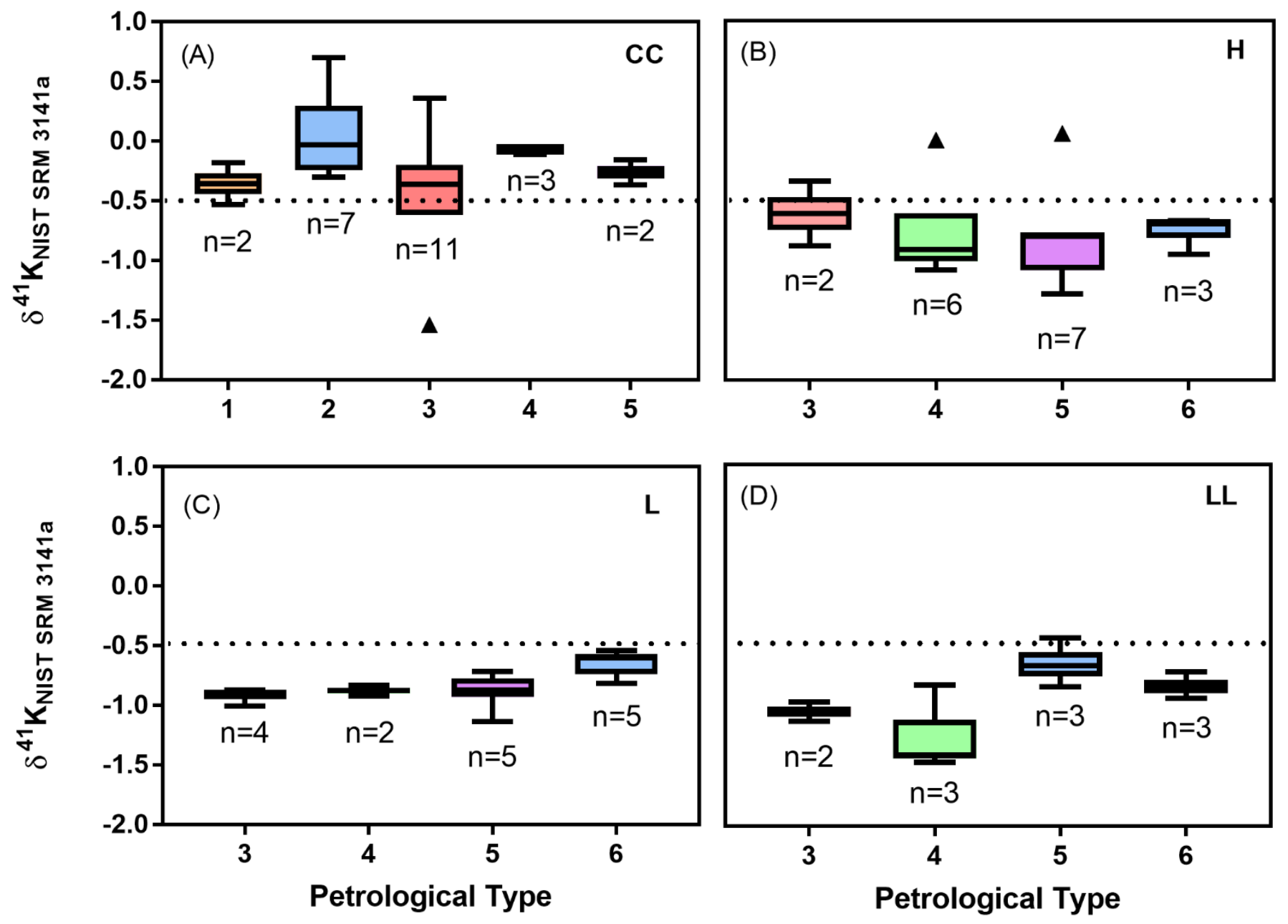

Figure 5 

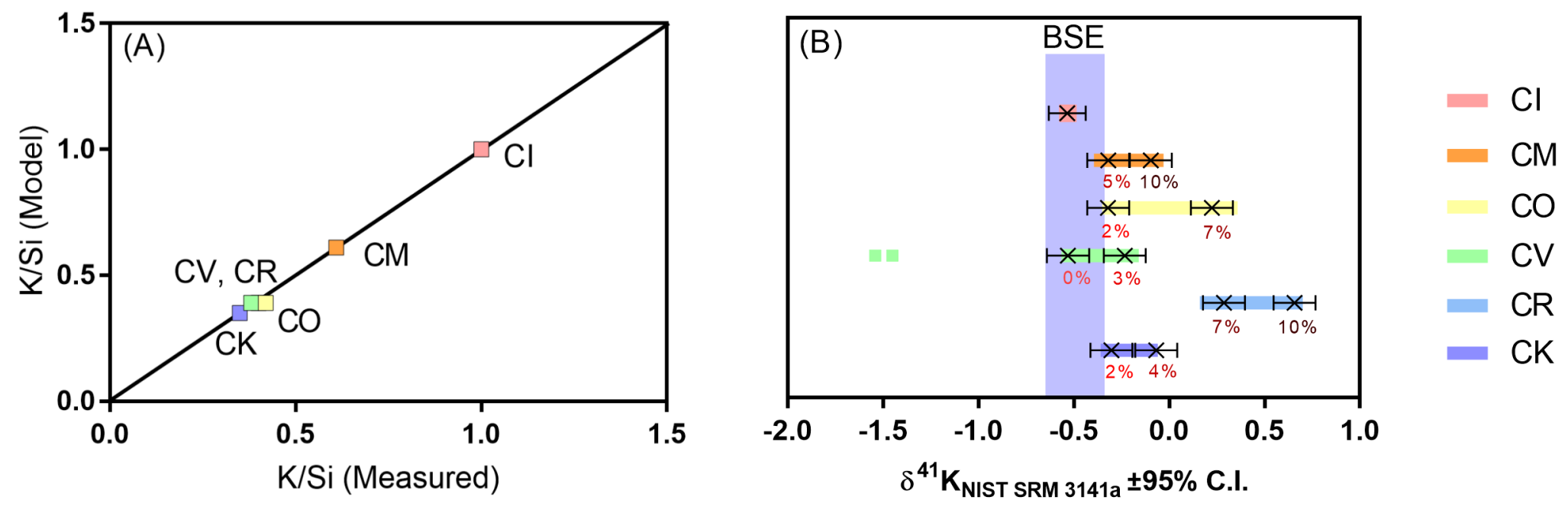

Figure 6 

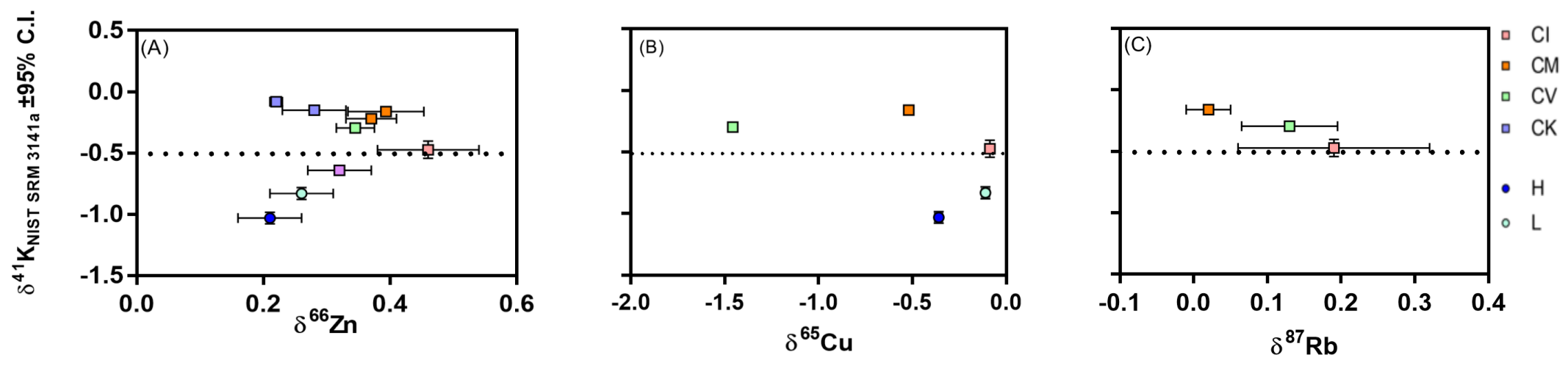

Figure 7 

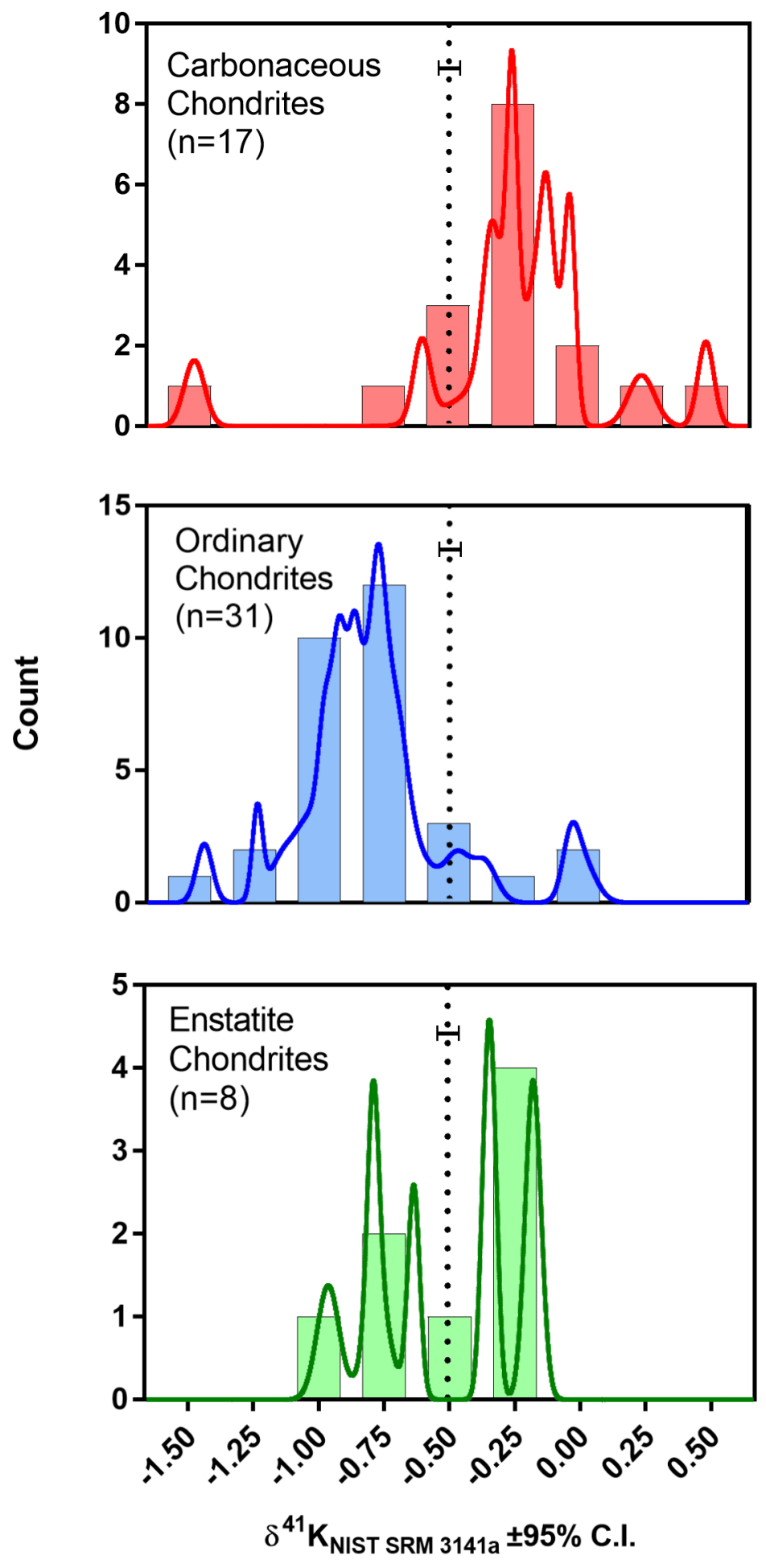

Figure 8 


\section{Online Supplementary Material}

for

\section{Potassium Isotope Compositions of Carbonaceous and Ordinary Chondrites: Implications on the Origin of Volatile Depletion in the Early Solar System}

Hannah Bloom ${ }^{1}$, Katharina Lodders ${ }^{1}$, Heng Chen ${ }^{1,2}$, Chen Zhao ${ }^{1,3}$, Zhen Tian ${ }^{1}$, Piers Koefoed $^{1}$, Mária K. Petö ${ }^{4}$, Yun Jiang ${ }^{5,6}$, and Kun Wang (王昆 $)^{{ }^{*}}$

${ }^{1}$ Department of Earth and Planetary Sciences and McDonnell Center for the Space Sciences, Washington University in St. Louis, One Brookings Drive, St. Louis, MO 63130, USA

${ }^{2}$ Lamont-Doherty Earth Observatory, Columbia University, Palisades, NY 10964, USA

${ }^{3}$ Faculty of Earth Sciences, China University of Geosciences, Wuhan, Hubei 430074, China

${ }^{4}$ Konkoly Observatory, Research Center for Astronomy and Earth Sciences, H-1121

Budapest, Hungary

${ }^{5}$ CAS Key Laboratory of Planetary Sciences, Purple Mountain Observatory, Chinese Academy of Sciences, Nanjing 210008, China

${ }^{6}$ CAS Center for Excellence in Comparative Planetology, China

*Corresponding author email: wangkun@wustl.edu

Accepted version

\section{Geochimica et Cosmochimica Acta}

\section{How to cite:}

Bloom, H., Lodders, K., Chen, H., Zhao, C., Tian, Z., Koefoed, P., Pető, M. K., Jiang, Y., and Wang, K. (2020) Potassium isotope compositions of carbonaceous and ordinary chondrites: Implications on the origin of volatile depletion in the early solar system. Geochimica et Cosmochimica Acta, in press. 


\section{Effect of cosmic-ray radiation on potassium isotopes of chondrites.}

It is well known that meteorites have experienced galactic and solar cosmic-ray radiation while traveling through space. The cosmic-ray-induced spallation reactions can change the isotope compositions of $\mathrm{K}$ in meteorites, particularly in iron meteorites (e.g., Voshage 1978). All three isotopes of $\mathrm{K}\left({ }^{39} \mathrm{~K},{ }^{40} \mathrm{~K}\right.$, and $\left.{ }^{41} \mathrm{~K}\right)$ can be generated via interaction of cosmic rays and target elements (mainly $\mathrm{Fe}$ and $\mathrm{Ni}$ ) and the $\delta^{41} \mathrm{~K}$ range of iron meteorites could vary by as much as $1,000 \%$ (Voshage et al., 1983). Therefore, the ${ }^{41} \mathrm{~K} /{ }^{40} \mathrm{~K}-{ }^{3} \mathrm{He} /{ }^{21} \mathrm{Ne}$ radiation exposure dating method has been applied routinely to iron meteorites (e.g., Voshage 1978). However, for exposure ages below $100 \mathrm{Myr}$ the small indigenous $\mathrm{K}$ content in iron meteorites (typically $10 \mathrm{ppm}$ ) significantly increases the uncertainty of the method.

In contrast to iron meteorites where i) the main target elements $(\mathrm{Fe}, \mathrm{Ni})$ are abundant, ii) indigenous $\mathrm{K}$ contents are negligible, and iii) exposure ages are long (up to 1100 Myr, e.g., Voshage 1967), the OCs and CCs have i) much lower Fe abundance (19-31 wt.\%), ii) much higher indigenous K content ( 300-900 ppm, Table 1 and 2), and iii) significantly shorter exposure times to galactic cosmic rays (typically between 0.1 to 80 Myr; Marti and Graf 1992). Therefore, the influence of cosmogenic $\mathrm{K}$ in stony meteorites will be much less evident (if even resolvable). Indeed, a previous survey study on $\mathrm{K}$ isotopes show that there is no $\mathrm{K}$ isotope variation observed among stony meteorites due to cosmogenic effect within their $\sim 0.5 \%$ best analytical uncertainties (Humayun and Clayton, 1995). 
In addition to spallation by primary particles, secondary neutron capture reactions are another possible way to change the isotopic compositions of $\mathrm{K}$ in meteorites. Secondary thermal neutrons are also products of cosmic-ray spallation (e.g., on target element $\mathrm{Fe})$. The neutron capture reaction ${ }^{40} \mathrm{Ca}(\mathrm{n}, \gamma)^{41} \mathrm{Ca}$ would generate radioactive ${ }^{41} \mathrm{Ca}$, which will eventually decay to ${ }^{41} \mathrm{~K}$ (half-life: $0.1 \mathrm{Myr}$ ). This decay is almost instantaneous compared to the long irradiation durations for most of the chondrites (up to 80 Myrs; Graf and Marti 1995). This neutron capture effect would be more pronounced in high $\mathrm{Ca} / \mathrm{K}$ samples, such as some $\mathrm{CCs}$ that contain abundant calcium aluminum-rich inclusions (CAIs). The previous survey study on $\mathrm{K}$ isotopes did not observe any $\mathrm{K}$ isotope variation among individual $\mathrm{CCs}$ and OCs regardless their $\mathrm{Ca} / \mathrm{K}$ ratios within the $\sim 0.5 \%$ best analytical uncertainties (Humayun and Clayton, 1995). Nevertheless, with the improved analytical precision $(\sim 0.05 \%)$ in this study, we have observed resolvable variations of $\delta^{41} \mathrm{~K}$ among individual CCs and OCs (see Figure 2), and it could be that some of the variation is due to cosmic-ray radiation effects through either direct spallation or secondary neutron-capture reaction.

The $\mathrm{Fe} / \mathrm{K}$ and $\mathrm{Ca} / \mathrm{K}$ ratios in different chemical groups of chondrites vary, but within the same chemical groups the $\mathrm{Fe} / \mathrm{K}$ and $\mathrm{Ca} / \mathrm{K}$ ratios do not vary significantly (Lodders and Fegley, 1998). Hence, the duration of the cosmic ray irradiation would be the main controlling factor for any variations of $\delta^{41} \mathrm{~K}$ among meteorites from the same chemical group. For example, the cosmic-ray exposure ages of OCs vary from less than 1 Myr, to longer than $80 \mathrm{Myr}$, with peaks at 6-10 Myr (H), $15 \mathrm{Myr}$ (LL) and $40 \mathrm{Myr}$ (L) (Graf and Marti, 1995). Among CCs, the CI and CM chondrites have the shortest cosmicray exposure ages (typically $<2 \mathrm{Myr}$ ) compared to $\mathrm{CV}$, $\mathrm{CK}$ and $\mathrm{CO}$ chondrites (averages: 
$13 \pm 10,23 \pm 14$, and $22 \pm 18 \mathrm{Myr}$, respectively; Eugster et al. 2006). As shown in Figure 2 , there is no obvious correlation between the average cosmic-ray exposure ages of each group and their $\mathrm{K}$ isotopes compositions. For individual meteorites from each group, we plot their K isotopes versus cosmic-ray exposure ages in Supplementary Figure S1. Again, we observe no obvious trend of $\mathrm{K}$ isotope compositions of individual meteorites versus their cosmic-ray exposure ages. Although cosmogenic spallation or secondary neutron capture reactions remain a possible source of variations in the $\mathrm{K}$ isotope compositions of chondrites, such effects cannot be resolved within the current best analytical precisions. 


\section{REFERENCES}

Dalcher N., Caffee M. W., Nishiizumi K., Welten K. C., Vogel N., Wieler R. and Leya I. (2013) Calibration of cosmogenic noble gas production in ordinary chondrites based on ${ }^{36} \mathrm{Cl}-{ }^{36} \mathrm{Ar}$ ages. Part 1: Refined produced rates for cosmogenic ${ }^{21} \mathrm{Ne}$ and ${ }^{38} \mathrm{Ar}$. Meteorit. Planet. Sci. 48, 1841-1862.

Eugster O. (1988) Cosmic-ray production rates for ${ }^{3} \mathrm{He},{ }^{21} \mathrm{Ne},{ }^{38} \mathrm{Ar},{ }^{83} \mathrm{Kr}$, and ${ }^{126} \mathrm{Xe}$ in chondrites based on ${ }^{81} \mathrm{Kr}-\mathrm{Kr}$ exposure ages. Geochim. Cosmochim. Acta 52, 16491662.

Eugster O., Herzog G. F., Marti K. and Caffee M. W. (2006) Irradiation Records, Cosmic-Ray Exposure Ages, and Transfer Times of Meteorites. In Meteorites and the Early Solar System II pp. 829-851.

Graf T. H., Caffee M. W., Marti K., Nishiizumi K. and Ponganis K. V. (2001) Dating collisional events: ${ }^{36} \mathrm{Cl}^{36} \mathrm{Ar}$ exposure ages of $\mathrm{H}$-Chondritic metals. Icarus 150, $181-$ 188.

Graf T. and Marti K. (1995) Collisional history of H chondrites. J. Geophys. Res. 100, 21247.

Graf T. and Marti K. (1994) Collisional records in LL-chondrites. Meteoritics 29, 643648.

Herpers U., Vogl S., Signer P., Wieler R., Beer J. and Wolfli W. (1989) Cosmogenic radionuclides and Noble gases in Allan Hills C-chondrites. In Workshop on Differences Between Antarctic and non-Antarctic Meteorites pp. 46-48.

Herzog G. F., Vogt S., Albrecht A., Xue S., Fink D., Klein J., Middleton R., Weber H. W. and Schultz L. (1997) Complex exposure histories for meteorites with "short" exposure ages. Meteorit. Planet. Sci. 32, 413-422.

Hintenberger H., König H., Schultz L. and Wänke H. (1964) Radiogene, spallogene und primordiale edelgase in steinmeteoriten. Zeitschrift fur Naturforsch. - Sect. A J. Phys. Sci. 19, 327-341.

Humayun M. and Clayton R. N. (1995) Potassium isotope cosmochemistry - geneticimplications of volatile element depletion. Geochim. Cosmochim. Acta 59, 21312148.

Lavielle B., Toé S. and Gilabert E. (1997) Noble gas measurements in the L/LL5 chondrite Knyahinya. Meteorit. Planet. Sci. 32, 97-107.

Leya E., Graf T. H., Nishiizumi K. and Wieler R. (2001) Cosmic-ray production rates of helium, neon and argon isotopes in $\mathrm{H}$ chondrites based on chlorine-36/argon-36 ages. Meteorit. Planet. Sci. 36, 963-973.

Lodders K. and Fegley B. (1998) The Planetary Scientist's Companion., Oxford University Press, New York.

Marti K. and Graf T. (1992) Cosmic-ray exposure history of ordinary chondrites. Annu. Rev. Earth Planet. Sci. 20, 221-243.

Mazor E., Heymann D. and Anders E. (1970) Noble gases in carbonaceous chondrites. Geochim. Cosmochim. Acta 34, 781-824.

Nishiizumi K., Arnold J. R., Caffee M. W., Finkel R. C., Southon J. R., Nagai H., Honda M., Sharma P., Imamura M. and Kobayashi K. (1993) Expoure ages of carbonaceous chondrites. In 24th Lunar and Planetary Science Conference pp. $1085-1086$.

Scherer P. and Schultz L. (2000) Noble gas record, collisional history, and pairing of CV, 
$\mathrm{CO}, \mathrm{CK}$, and other carbonaceous chondrites. Meteorit. Planet. Sci. 35, 145-153. Voshage H. (1967) Bestrahlungsalter und Herkunft der Eisenmeteorite. Zeitschrift für Naturforsch. A 22, 477.

Voshage H. (1978) Investigations on cosmic-ray-produced nuclides in iron meteorites, 2. New results on ${ }^{41} \mathrm{~K} /{ }^{40} \mathrm{~K}-{ }^{4} \mathrm{He} /{ }^{21} \mathrm{Ne}$ exposure ages and the interpretation of age distributions. Earth Planet. Sci. Lett. 40, 83-90.

Voshage H., Feldmann H. and Braun O. (1983) Investigations of Cosmic-Ray-Produced Nuclides in Iron Meteorites: 5. More Data on the Nuclides of Potassium and Noble Gases, on Exposure Ages and Meteoroid Sizes. Zeitschrift für Naturforsch. A 38. 


\section{Supplementary Figure Captions:}

Supplementary Figure S1. The bulk K isotopic compositions of carbonaceous chondrites and ordinary chondrites vs. cosmic-ray exposure ages (A) or vs. cosmic-ray

5 exposure ages $\left(\mathrm{T}_{\mathrm{e}}\right)^{*}[\mathrm{Fe}]^{*}[\mathrm{Ca}] /[\mathrm{K}](\mathrm{B})$. Exposure age estimates (Hintenberger et al., 1964; Mazor et al., 1970; Eugster, 1988; Herpers et al., 1989; Nishiizumi et al., 1993; Graf and Marti, 1994; Graf and Marti, 1995; Lavielle et al., 1997; Herzog et al., 1997; Scherer and Schultz, 2000; Graf et al., 2001; Leya et al., 2001; Dalcher et al., 2013) are based on cosmogenic noble gas nuclide $\left(\mathrm{T}_{3}, \mathrm{~T}_{21}\right.$ and $\left.\mathrm{T}_{38}\right)$ and ${ }^{36} \mathrm{Cl} /{ }^{36} \mathrm{Ar}$ methods. A $15 \%$ minimum relative error was assigned to $\mathrm{T}_{3}$ and $\mathrm{T}_{21}$ values, following Eugster (1988). 

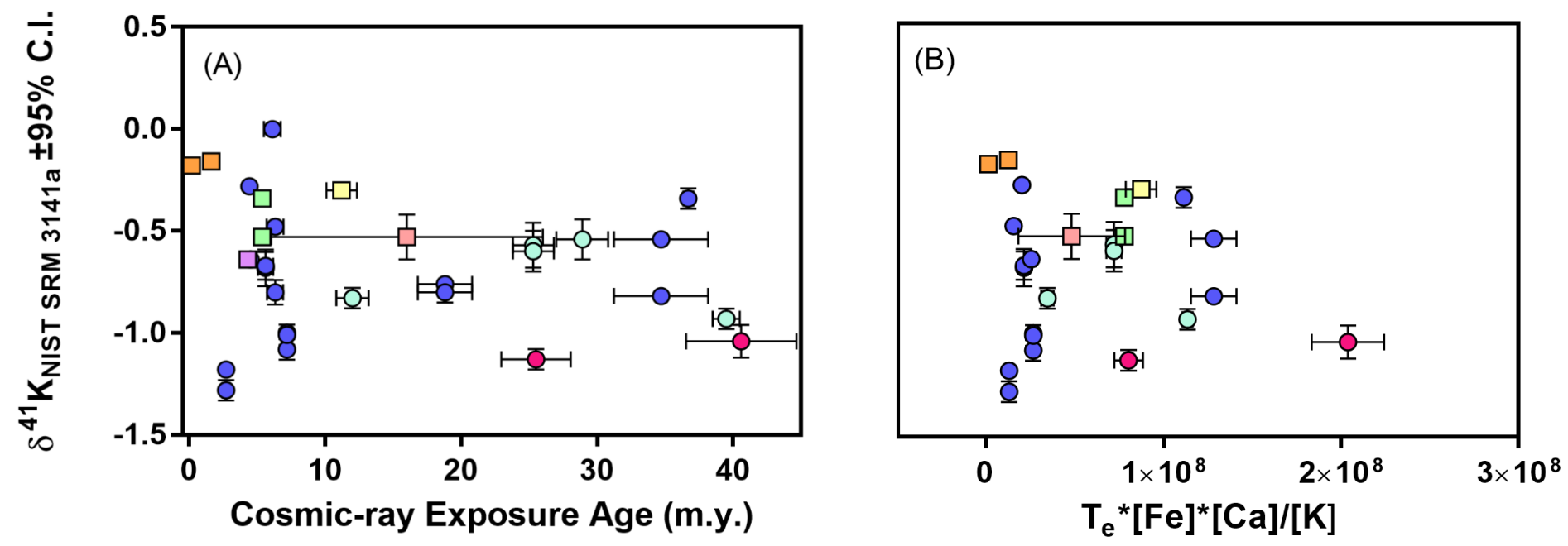

$\square \mathrm{Cl}$

- $\mathrm{CM}$

$\mathrm{CO}$

- CV

口 $\mathrm{CH}$

- $\mathrm{H}$

O L

- LL

Supplementary Figure S1 